University of Nebraska - Lincoln

DigitalCommons@University of Nebraska - Lincoln

\title{
Development of soft computing and applications in agricultural and biological engineering
}

\author{
Yanbo Huang \\ USDA-ARS, yanbo.huang@ars.usda.gov \\ Yubin Lan \\ USDA-ARS
}

Steven J. Thomson

USDA-ARS

Alex Fang

Texas A\&M University

Wesley C. Hoffmann

USDA-ARS

See next page for additional authors

Follow this and additional works at: https://digitalcommons.unl.edu/usdaarsfacpub

Huang, Yanbo; Lan, Yubin; Thomson, Steven J.; Fang, Alex; Hoffmann, Wesley C.; and Lacey, Ronald E., "Development of soft computing and applications in agricultural and biological engineering" (2010).

Publications from USDA-ARS / UNL Faculty. 2086.

https://digitalcommons.unl.edu/usdaarsfacpub/2086

This Article is brought to you for free and open access by the U.S. Department of Agriculture: Agricultural Research Service, Lincoln, Nebraska at DigitalCommons@University of Nebraska - Lincoln. It has been accepted for inclusion in Publications from USDA-ARS / UNL Faculty by an authorized administrator of DigitalCommons@University of Nebraska - Lincoln. 


\section{Authors}

Yanbo Huang, Yubin Lan, Steven J. Thomson, Alex Fang, Wesley C. Hoffmann, and Ronald E. Lacey 
Review

\title{
Development of soft computing and applications in agricultural and biological engineering
}

\author{
Yanbo Huang a,*, Yubin Lan ${ }^{\mathrm{b}}$, Steven J. Thomson ${ }^{\mathrm{a}}$, Alex Fang ${ }^{\mathrm{c}}$, Wesley C. Hoffmann ${ }^{\mathrm{b}}$, Ronald E. Lacey ${ }^{\mathrm{d}}$ \\ a USDA-ARS, CPSRU, 141 Experiment Station Road, Stoneville, MS 38776, United States \\ b USDA-ARS, APMRU, 2771 FEB Road, College Station, TX 77845, United States \\ ' Engineering Technology and Industrial Distribution, Texas AE'M University, College Station, TX 77843, United States \\ ${ }^{\mathrm{d}}$ Biological and Agricultural Engineering, Texas A\&M University, College Station, TX 77843, United States
}

\section{A R T I C L E I N F O}

\section{Article history:}

Received 1 August 2009

Received in revised form 9 January 2010

Accepted 25 January 2010

\section{Keywords:}

Soft computing

Fuzzy logic

Artificial neural networks

Genetic algorithms

Crop management

Precision agriculture

\begin{abstract}
A B S T R A C T
Soft computing is a set of "inexact" computing techniques, which are able to model and analyze very complex problems. For these complex problems, more conventional methods have not been able to produce cost-effective, analytical, or complete solutions. Soft computing has been extensively studied and applied in the last three decades for scientific research and engineering computing. In agricultural and biological engineering, researchers and engineers have developed methods of fuzzy logic, artificial neural networks, genetic algorithms, decision trees, and support vector machines to study soil and water regimes related to crop growth, analyze the operation of food processing, and support decision-making in precision farming. This paper reviews the development of soft computing techniques. With the concepts and methods, applications of soft computing in the field of agricultural and biological engineering are presented, especially in the soil and water context for crop management and decision support in precision agriculture. The future of development and application of soft computing in agricultural and biological engineering is discussed.
\end{abstract} Published by Elsevier B.V.

\section{Contents}

1. Introduction .

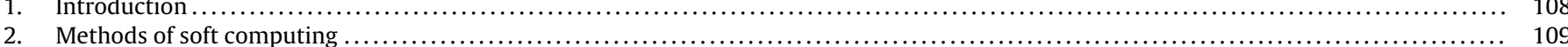

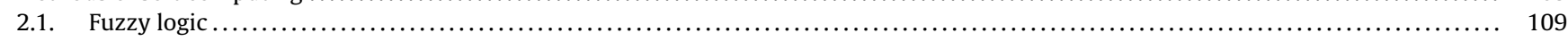

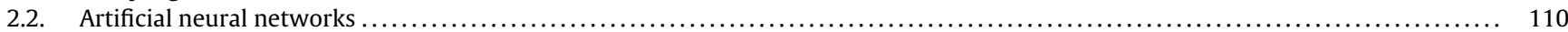

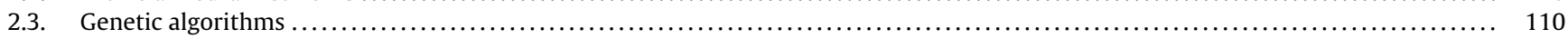

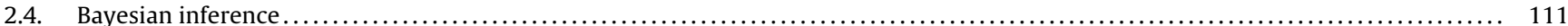

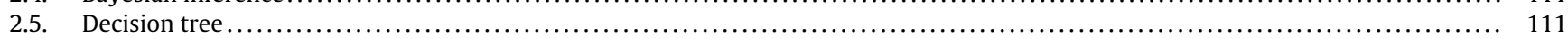

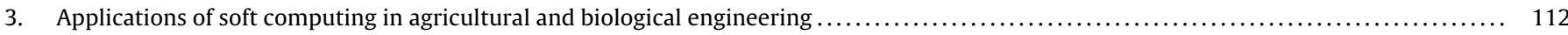

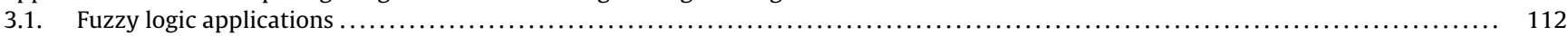

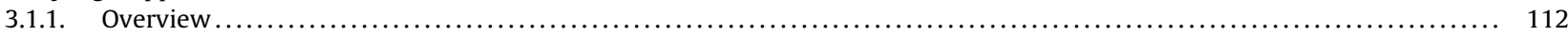

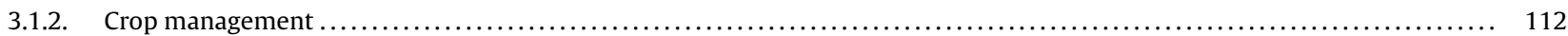

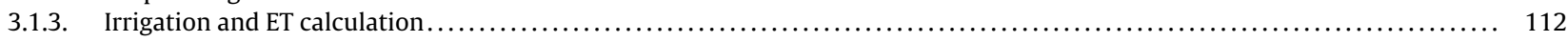

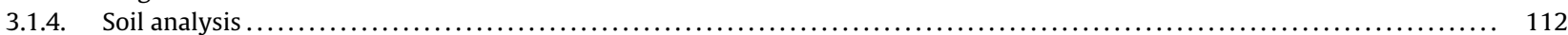

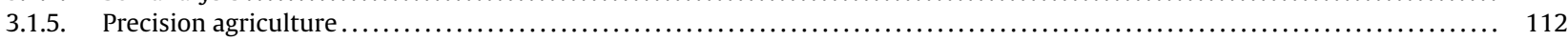

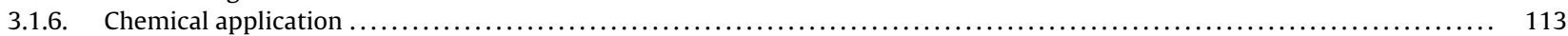

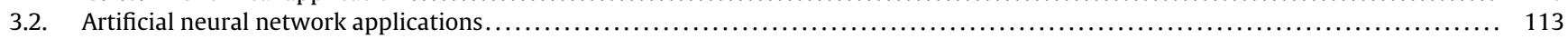

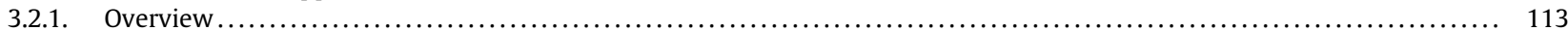

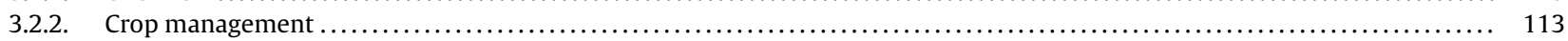

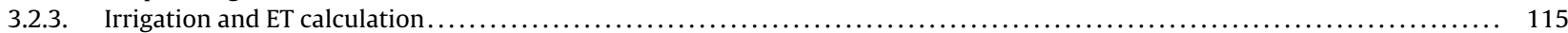

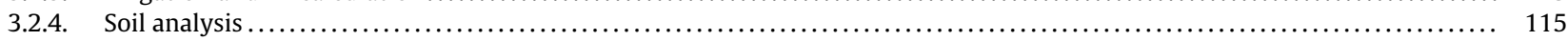

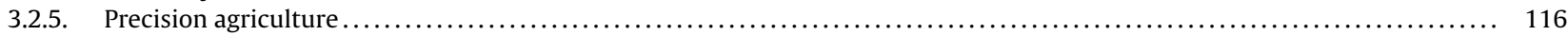

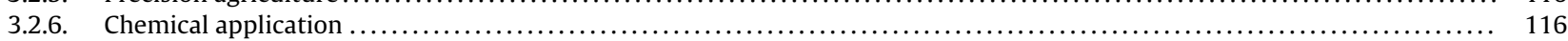

\footnotetext{
* Corresponding author. Tel.: +1 662686 5354; fax: +1 6626865372.

E-mail address: yanbo.huang@ars.usda.gov (Y. Huang).
} 


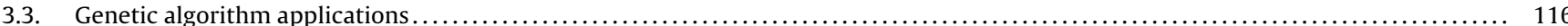

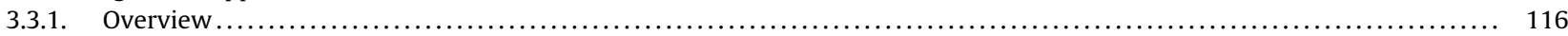

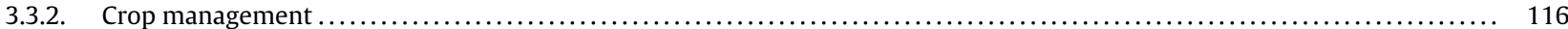

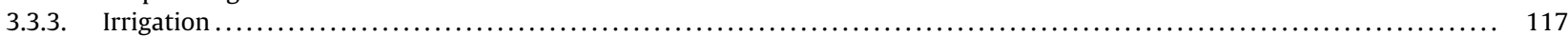

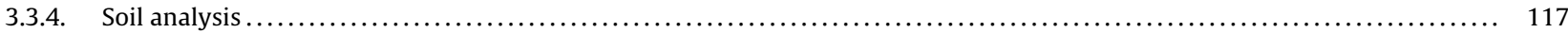

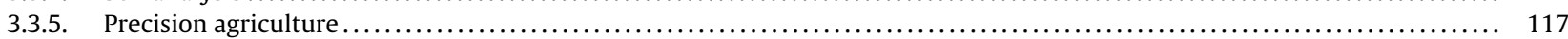

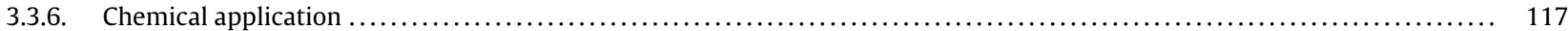

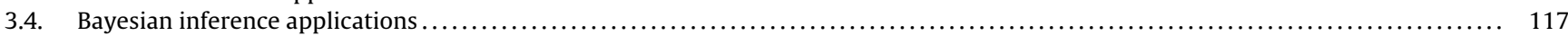

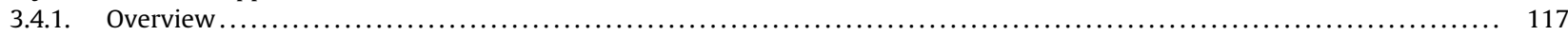

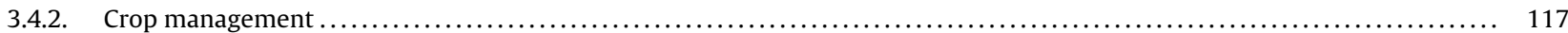

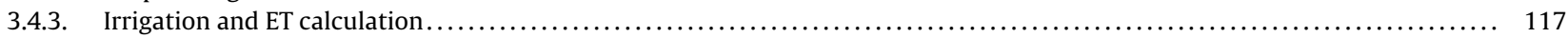

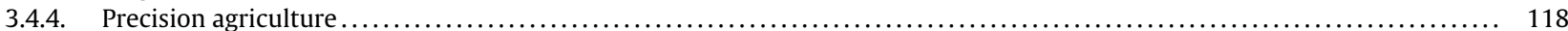

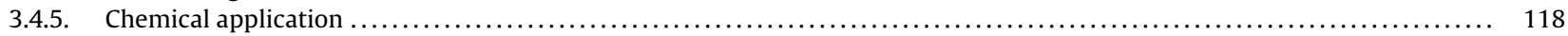

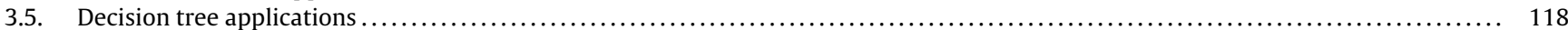

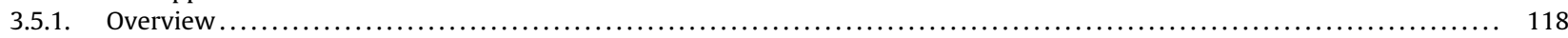

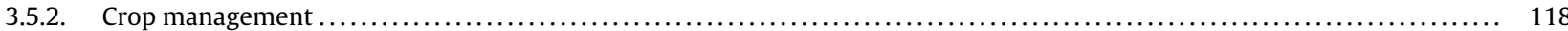

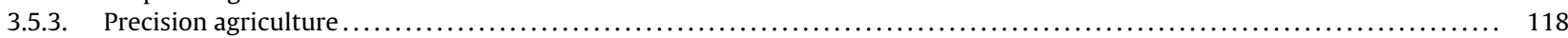

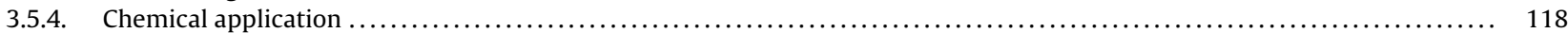

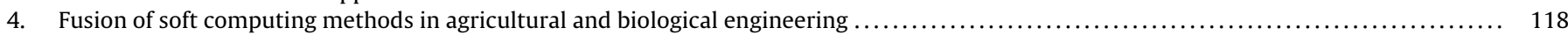

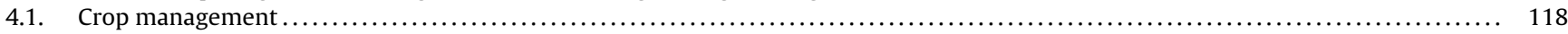

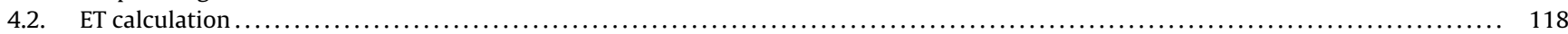

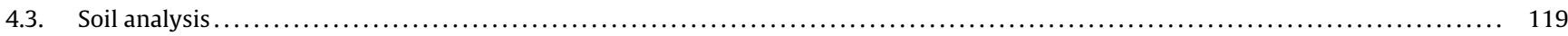

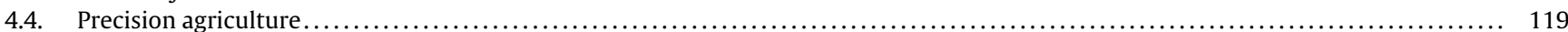

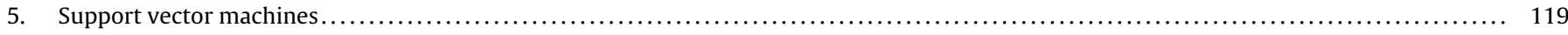

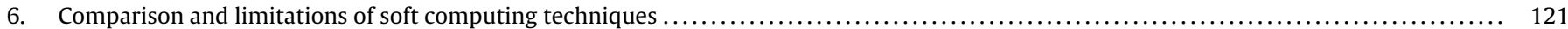

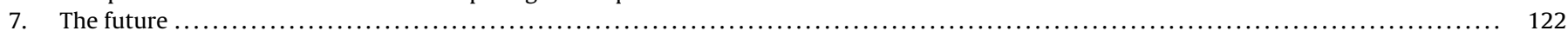

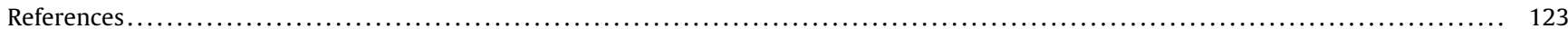

\section{Introduction}

Soft computing is a set of computing techniques, such as Fuzzy Logic (FL), Artificial Neural Networks (ANNs), and Genetic Algorithms (GAs). These computing techniques, unlike hard computing, which refers to a huge set of conventional techniques such as stochastic and statistical methods, offer somewhat "inexact" solutions of very complex problems through modeling and analysis with a tolerance of imprecision, uncertainty, partial truth, and approximation. In effect, soft computing is an integration of biological structures and computing techniques. FL developes multi-valued, non-numeric linguistic variables for modeling human reasoning in an imprecise environment. ANNs provides configurations made up of interconnecting artificial neurons that mimic the properties of biological neurons. GAs are a way of solving problems by mimicking the same processes nature uses through selection, recombination and mutation.

Soft computing is used to achieve tractability, robustness, and provide a low cost solution with a tolerance of imprecision, uncertainty, partial truth, and approximation. This makes soft computing capable of solving problems that more conventional methods have not yet been able to provide in a cost-effective, analytical, or complete manner. Among soft computing techniques, FL appears to be the first one that has established fundamental ideas of soft computing (Zadeh, 1965, 1973, 1981). The established basic ideas have influenced other techniques that arrived later. In 1986, the Parallel Distributed Processing (PDP) research group published a series of results and algorithms (Rumelhart and McClelland, 1986). This work gave a strong impetus to the study of mechanisms and structure of the brain and provided the catalyst for much of the subsequent research and application of ANNs. This can be viewed as the point at which ANNs became one of the soft computing techniques. GAs were developed by John Holland in 1975 and popularized by his student, David Goldberg (Goldberg, 1989). Currently, FL, ANNs, and GAs are considered as core techniques of soft computing.The current list of soft computing techniques also includes machine learning, probabilistic reasoning, and chaos theory.
In the last three decades, soft computing has been extensively studied and applied for scientific research and engineering computing. Although applications of soft computing techniques were successful in solving problems, the methodology still has been advancing to provide new approaches for more efficient, robust, and reliable solutions. Support Vector Machines (SVMs) (Burges, 1998; Cristianini and Taylor, 2000) emerged as a set of supervised generalized linear classifiers and often provide higher classification accuracies than multilayer perceptron ANNs. SVMs have attracted greater interest in recent years. Method fusion is another advancement in soft computing development, which combines or cascades different soft computing techniques to improve system performance over any individual technique. Neuro-fuzzy systems are a typical example of such a fusion (Takagi and Hayashi, 1991; Horikawa et al., 1992; Nie and Linkens, 1992; Simpson and Jahns, 1993; Mitra and Pal, 1994; Jang and Sun, 1995). The behavior and stability of hard computing are more predictable. The computational burden of algorithms is typically either low or moderate. Thus, it is natural to view soft computing and hard computing as complementary. The fusion of them has great potential for developing high-performance, cost-effective, and reliable computing schemes that provide innovative solutions to problems (Ovaska et al., 2002).

In agricultural and biological engineering, there has been some early research and applications of soft computing (Whittaker et al., 1991; Zhang and Litchfield, 1992; Eerikäinen et al., 1993) and interest in soft computing has grown steadily in the last decade. A summary of papers and reports were collected from various sources, particularly through searches of the technical library of the ASABE (American Society of Agricultural and Biological Engineers) (http://asae.frymulti.com/) and the National Agricultural Library of USDA (United States Department of Agriculture) (http://www.nal.usda.gov/). It was found that, from the early1990 s to 2008, there have been 165 reports and papers (65 peer reviewed) on FL, 348 (193 peer reviewed) on ANNs, and 83 (36 peer reviewed) on GAs. It is interesting to note that 20 reports and papers (13 peer reviewed) were written on SVMs from 2003 to present, 7 ( 2 peer reviewed) of which were published in 2008. This may signify 
more interest in soft computing in the next decade in agricultural and biological engineering. Soil and water studies focused on crop management and decision support systems for precision agriculture include specialties such as those highlighted in Geoderma, a global journal of soil science, SSSAJ (Soil Science Society of America Journal), Journal of Soil \& Water Conservation, and Journal of Precision Agriculture.

In agricultural and biological engineering, researchers and engineers have developed methods for FL, ANNs, GAs, Bayesian Inference (BI), Decision Tree (DT), and SVMs to study soil and water regimes related to crop growth, analyze the operation of food processing, and support decision-making in precision farming. They have also used fusion techniques that include FL, ANN and GA in solving problems. However, we have not found applications where fusion was applied to soft computing and hard computing. This could be a research topic with great potential.

This paper briefly reviews the development of soft computing techniques. With the concepts and methods, applications of soft computing in the field of agricultural and biological engineering are presented. The future of the development and application of soft computing in agricultural and biological engineering is discussed, especially in the soil and water context for crop management and in decision support in precision agriculture.

\section{Methods of soft computing}

In general, soft computing includes the methods of $\mathrm{FL}$, neuro-computing, evolutionary computing, probabilistic computing, belief networks, chaotic systems, and parts of learning theory (http://www.cs.berkeley.edu/ zadeh/acprco.html). For research and development in agricultural and biological engineering, primary methods of significant utility include FL, ANNs, GAs, BI and DT.

ANNs are model architectures and learning algorithms of neurocomputing. GAs are a particular class of evolutionary computation. $\mathrm{BI}$ is a method to realize probabilistic computing. DT is one of the interesting and commonly used architectures used for learning, reasoning and organization of datasets in soft computing. FL, ANNs, GAs, BI and DT have been widely applied for research and development in agricultural and biological engineering, especially within the last decade.

\subsection{Fuzzy logic}

FL is a form of multi-valued logic derived from fuzzy set theory to deal with reasoning that is approximate, rather than precise. In contrast to yes/no or 0/1 binary logic (crisp), FL provides a set of membership values inclusively between 0 and 1 to indicate the degree of truth (fuzzy). Fig. 1 shows the difference between a crisp set and a fuzzy set by comparing the characteristic functions of the two sets. For the crisp set (Fig. 1(a)) the characteristic function of $A$ is assigned a value of 1 or 0 to each value in $X$, a value set of a physical property. 1 for $A$ indicates that corresponding values in $X$ belong to the set $A$. 0 for $A$ indicates that corresponding values in $X$ do not belong to the set $A$. The concept of the crisp set is sufficient for many applications but is not for some applications that require flexibility. In the fuzzy set the characteristic function of $A$ is assigned a value between 0 and 1 , including 0 and 1 , to each value in $X .1$ or 0 for $A$ still indicate that corresponding values in $X$ belong or do not belong to the set $A$. The values between 0 and 1 for $A$ indicate that the corresponding values in $X$ belong to the set $A$ in a certain degree from low, medium, to high with the increase of the $A$ value. Fig. 1(b) shows a typical characteristic function of the fuzzy set. With the characteristic function the membership function for a fuzzy set can be constructed to quantify the magnitude of belong-

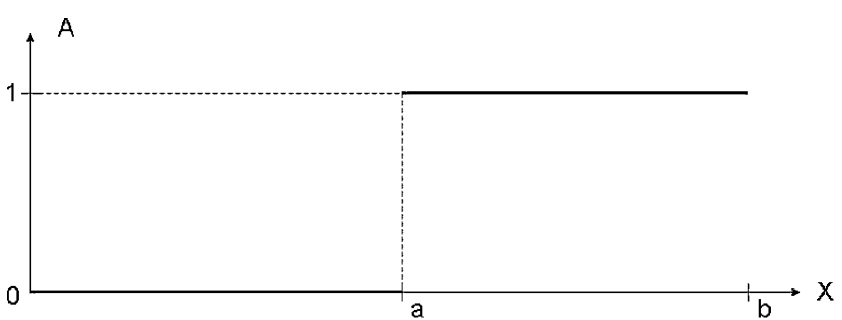

(a) Characteristic function of a crisp set

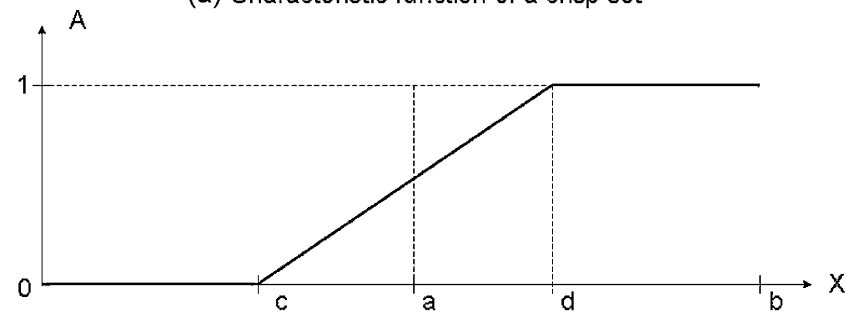

(b) Characteristic function of a fuzzy set

Fig. 1. Characteristic functions of crisp and fuzzy sets $(b>d>a>c>0)$. Characteristic function of a crisp set (a) and fuzzy set (b)

ing of each input. The membership functions may be different in shape and interval. The logic operations such as AND and OR can implemented with the different membership functions to generate a resultant membership function.

In process modeling and control, systems that are ill-defined and with uncertainties can be modeled with a fuzzy inference system employing fuzzy 'If-Then' rules to quantify human knowledge and reasoning processes without employing precise quantitative analyses. The fuzzy inference system should include the following functional blocks (Jang, 1993):

- a fuzzification interface that transforms the crisp inputs into degrees of match with linguistic values;

- a knowledge base that includes

- a rule base containing a number of fuzzy 'If-Then' rules;

o a database that defines the membership functions of the fuzzy sets used in the fuzzy rules;

- a decision-making unit that performs the inference operations on the rules; and

- a defuzzification interface that transforms the fuzzy results of the inference into a crisp output.

Although some preceding work has been indicated (Wilkinson, 1963), Dr. Lotfi Zadeh has been generally considered as the first person who introduced FL to the world. In 1965, Dr. Zadeh axiomatized fuzzy set theory (Zadeh, 1965). FL is an interface between logic and human reasoning. Humans have a remarkable capability to reason and make decisions in an environment of uncertainty, imprecision, incompleteness of information, and partiality of knowledge, truth and class membership. FL is for formalization/mechanization of this capability. FL mimics human control logic. It can be built into anything from small, hand-held products to large computerized process control systems. It uses an imprecise but very descriptive language to deal with input data as a human operator would. It is very robust and tolerant of operator and data input and often works when first implemented with little or no tuning.

FL has been applied to diverse fields since the 1970s with the sufficient development of small computing capability. It has been applied in such varied fields as control systems and artificial intelligence. In 1974, the first successful application of fuzzy logic to the control of a laboratory-scale process was reported (Mamdani and Assilian, 1975). Control of cement kilns was an early industrial application (Holmblad and Ostergaard, 1982). Since the first 
consumer product using fuzzy logic was marketed in 1987, the use of fuzzy control has increased substantially. A number of CAD (Computer-Aid Design) environments for fuzzy control design have emerged together with VLSI (Very-Large-Scale Integration) hardware for fast execution. Fuzzy control is being applied to various systems in the process industry (Santhanam and Langari, 1994; Tani et al., 1994), consumer electronics (Hirota, 1993; Bonissone, 1994), automatic train operation (Yasunobu and Miyamoto, 1985), traffic systems in general (Hellendoorn, 1993), and in other fields (Hirota, 1993; Terano et al., 1994).

Although FL was proposed by Professor Zadeh of University of California at Berkeley, FL has been gaining popularity only gradually in the United States. This may be due to disappointment with the unfulfilled promises of 'artificial intelligence' computing techniques in the 1980s (Khoshnevis and Chignell, 1985). However, at the same time, FL products have been aggressively built in Europe and Japan (EET, 1991; Smith, 1993). Still, the United States EPA (Environmental Protection Agency) has investigated fuzzy control for energy-efficient motors (Cleland et al., 1992). NASA (National Aeronautics and Space Administration) has studied fuzzy control for automated space docking (Ortega and Giron-Sierra, 1995). Boeing, General Motors, Allen-Bradley, Chrysler, Eaton, Whirlpool, and Maytag have also worked on fuzzy logic for use in low-power refrigerators, automated dishwashers, improved automotive transmissions, and energy-efficient electric motors.

Development of fuzzy systems has helped advance techniques for handling imprecision in soft computing. In 1992, the concept of soft computing was introduced (Zadeh, 1992). Dr. Zadeh envisioned soft computing as being concerned with modes of computing in which precision is traded for tractability, robustness and ease of implementation. Soft computing serves to highlight the emergence of computing methodologies in which the emphasis is on exploiting the tolerance for imprecision and uncertainty to achieve tractability, robustness, and low solution cost.

\subsection{Artificial neural networks}

ANNs provide a way to emulate biological neurons to solve complex problems in the same manner as the human brain. For many years, especially since the middle of the last century, interest in studying the mechanism and structure of the brain has been increasing. This increasing research interest has led to the development of new computational models, connectionist systems or ANNs, based on the biological background for solving complex problems like pattern recognition and fast information processing and adaptation. In the early 1940s, McCulloch and Pitts (1943), pioneers in the field, studied the potential and capabilities of interconnecting several basic components based on the model of a neuron. Later on, others like Hebb (1949), were concerned with the adaptation laws involved in neural systems. Rosenblatt (1958) coined the name "Perceptron" and devised an architecture, which has subsequently received much attention. Minsky and Papert (1969) later introduced a rigorous analysis of the Perceptron, of which they proved many properties and pointed out limitations of several related models. In the 1970s, the work of Grossberg (1976) came to prominence. His work, based on biological and psychological evidence, proposed several novel architectures of nonlinear dynamic systems. In the 1980s, Hopfield (1982) applied a particular nonlinear dynamic structure to solve problems in optimization. All of them conducted pioneer studies on the theoretical aspect of ANNs.

In 1986, the PDP (Parallel Distributed Processing) research group published a series of algorithms and results (Rumelhart and McClelland, 1986). This publication contains an article entitled "Learning Internal Representations by Error Propagation" (Rumelhart et al., 1986a). This article brought recognition to an

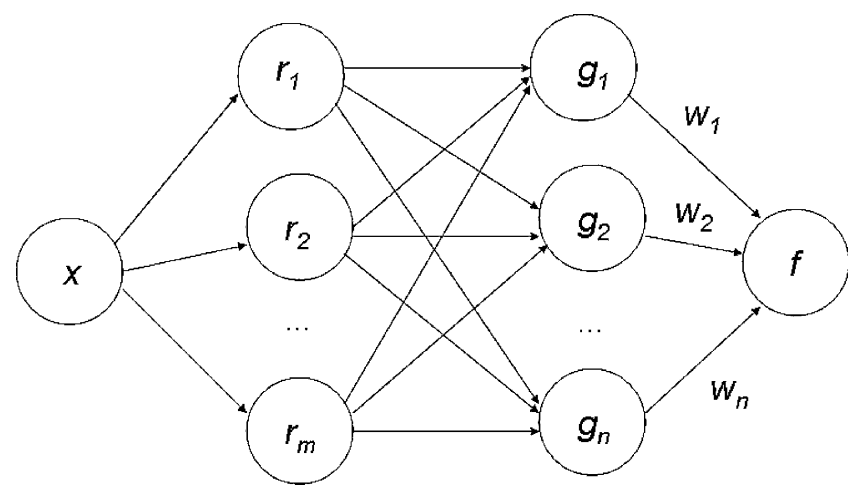

Fig. 2. ANN network structure.

ANN training algorithm named BackPropagation (BP), although it had already been described in Werbos (1974). This BP training algorithm implemented with the general delta rule (Rumelhart et al., 1986a, 1986b) gave a strong impulse to subsequent research and resulted in the largest body of research and applications in ANNs although many other ANN architectures and training algorithms have been developed and applied simultaneously.

The architecture, training/learning, and implementation of an ANN are a simplified version of the structure and activities of human brain. For problem solving, the human brain uses a web of interconnected processing units, neurons, to process information. Each of the neurons is autonomous, independent, and works asynchronously. The vast processing power inherent in biological neural structures has inspired the study of the structure itself as a model for organizing and designing man-made computing structures. Compared with conventional data processing methods, ANNs provide a model-free, adaptive, parallel-processing, and robust solution with fault and failure tolerance, learning, ability to handle imprecise and fuzzy information, and capability to generalize. An ANN is able to map process input and output without underlying assumption about the distribution of data. ANNs are powerful in data processing and analysis. In mathematics, ANNs are the models defining a function: $f(x) \mid X \rightarrow Y$. Each ANN model defines a class of such functions. In ANNs, the function $f(x)$ is defined by a combination of functions $g_{i}(x)$, which could be further defined by a combination of other functions $r_{i}(x)$, and so on. This recursive function definition in an ANN brings up a network structure for the interconnection of function units. The widely used function combination is the nonlinear weighted sum: $f(x)=A_{c}\left(\sum_{i=1}^{n} w_{i} g_{i}(x)\right)$, where $A_{c}()$ is a predefined activation function, such as the hyperbolic tangent function (Werbos, 1974; Rumelhart et al., 1986a, 1986b). Fig. 2 shows a two hidden-layer feedforward network between input $x$ and output $f$.

The feedforward network with a single hidden layer that contains a finite number of hidden neurons accompanied with an arbitrary activation function was proven to be a universal approximator on a compact subset of real $n$-dimensional Euclidean space $R^{n}$ (Hornik et al., 1989; Cybenko, 1989). This theory assures that ANNs can handle engineering problems, which are highly complex and nonlinear. ANNs provide a powerful method for practically accurate solutions of precisely or imprecisely formulated problems and for phenomena that are only understood through experimental data and field observations. ANNs have become the most popular soft computing methods for solving problems in engineering.

\subsection{Genetic algorithms}

Evolutionary computing is an Artificial Intelligence (AI) technique to solve combinatorial optimization problems. It is 


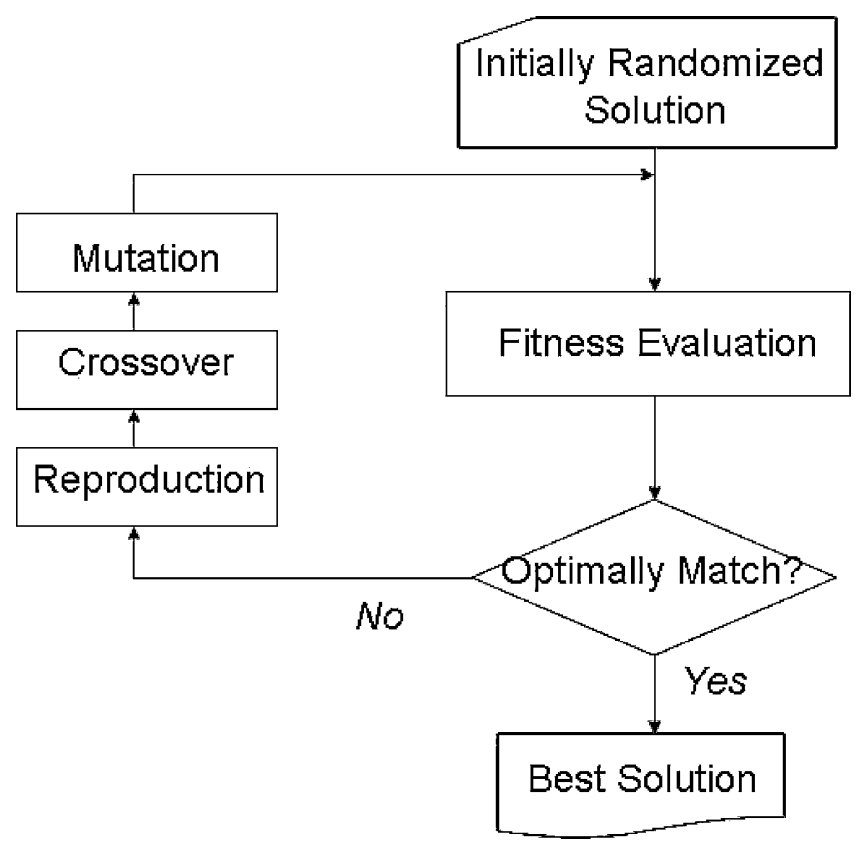

Fig. 3. Flowchart of GA operation.

implemented in iterative progress with the growth in a population selected in a guided random search using parallel processing to reach the desired point. This operation was inspired by biological mechanisms of evolution, which is similar to Darwin's theory on evolution (Darwin, 1859). There are a number of people who laid the theoretical foundations of evolutional computing: Lawrence J. Fogel and John Henry Holland in the United States (Fogel et al., 1966; Holland, 1975), and Ingo Rechenberg and Hans-Paul Schwefel in Germany (Rechenberg, 1973; Schwefel, 1981). Fogel is regarded as the father of evolutionary computing. Holland studied this method a little differently and named it a genetic algorithm. Then, one of Holland's students, David Goldberg, solved a difficult problem involving the control of gas-pipeline transmission using the method of GA in his dissertation (Goldberg, 1989). Goldberg's work greatly inspired subsequent research and applications of GA.

GA is an optimization and heuristic search technique that uses techniques inspired by evolutionary biology such as inheritance, mutation, selection, and crossover (also called recombination). GA works simultaneously on a set (population) of potential solutions (individuals) to the problem. The algorithm starts with a set of solutions (representing chromosomes) called a sub-population. The fitness to which solutions meet some performance criterion is evaluated and used to select "surviving" individuals that will "reproduce" a new, better sub-population. Then, the individuals will conduct alterations similar to the natural genetic mutation and crossover. The selection scheme makes the process towards high performance solutions. A careful selection of genetic algorithm structure and parameters can ensure a good chance of reaching the globally optimal solution after a reasonable number of iterations. Fig. 3 shows a flowchart of operational processes of GAs. GAs are computationally simple yet powerful enough to provide a robust search for difficult combinational search problems in complex spaces, without being stuck in local extremes (Goldberg, 1989). Therefore, GAs are powerful alternative tools to traditional optimization methods. GAs have been successfully used in many fields, such as scheduling (Wall, 1996; Lim and Sim, 2005), function optimization (Houck et al., 1998), machine learning (Goldberg and Holland, 1988; Grefenstette, 1994; Shapiro, 1998) and have become an important method of soft computing.

\subsection{Bayesian inference}

Probabilistic computing is a soft computing technique to perform probabilistic reasoning. The aim of probabilistic reasoning is to combine the capacity of probability theory to handle uncertainty to make inference with belief. Pearl (1988) made an important survey on this topic with an emphasis on Bayesian networks. Grunwald (1997) made a useful review also.

Bayesian approaches have been studied and applied extensively (Eddy, 1982; Edwards, 1982; Gigerenzer and Hoffrage, 1995; Jaynes, 1996; Lauritzen, 2003) by using Bayes's theorem (Bayes, 1763 ) in the process of probabilistic computation. Classical inference models do not permit the introduction of prior knowledge into the calculations. However, the use of prior knowledge would sometimes be useful to the process evaluation. BI (Bayesian Inference) is a statistical inference incorporating prior knowledge and prior probability distributions. In the process of BI evidence or observations are used to update the probability that a hypothesis may be true. Conventionally, binary hypothesis testing is used to statistically decide which hypothesis is true between two hypotheses. Alternatively, a Bayesian decision rule, such as minimum Bayes risk, minimum probability of error, or maximum a posteriori probability (MAP), depends on the prior probability of each hypothesis (Duda et al., 2001).

Bayesian inference is based on the Bayes' theorem (Bayes, 1763 ) that adjusts probabilities given new evidence: $P(H \mid E)=$ $P(E \mid H) P(H) / P(E)$ where is the specific hypothesis, $P(H)$ is the prior probability of $H, P(E \mid H)$ is the conditional probability of $E$ when $H$ happens to be true, and $P(E)$ is the marginal probability of $E$ (new evidence). The ratio $P(E \mid H) / P(E)$ represents the impact the evidence has on the belief in the hypothesis. When this ratio is large, a larger posterior probability of the hypothesis given the evidence will be produced by multiplying the prior probability of the hypothesis by this factor. When this ratio is small, a smaller posterior probability for $\mathrm{H}$ will be produced. In Bayesian inference, Bayes' theorem is used to measure how much new evidence should alter belief in a hypothesis.

Bayesian Networks have been accepted as tools for decisionmaking in complex situations within a variety of disciplines (Pearl, 1999; Charniak, 1991). Bayesian Networks are probabilistic graphical models. Each of the models characterizes a set of variables and their probabilistic independencies. The graphical, probabilistic models allow the structured representation of a cognitive process based on a link and node structure where the state of parent node predicts the state of the child node. Conditional probability tables are then used to relate the parent and child nodes using Bayesian statistical methods to predict their relationship. Dynamic Bayesian networks (Ghahramani, 1997) are the Bayesian networks that represent sequences of variables. These sequences are often values of time series or sequences of symbols (for example protein sequences).

\subsection{Decision tree}

DT (Decision Tree) is a popular method of machine learning. It was developed in the1960s (Magee, 1964) and comprises a treestructured arrangement of a set of attributes to evaluate and predict the output. In the operation of a DT, the algorithm is recursively looking for the attribute with the highest information gain, which is determined to evaluate first. DTs can be used to identify the strategy most likely to reach a goal. They can also be used as a descriptive means for calculating conditional probabilities. In operations research, a DT is a decision (classification) model (Hillier and Lieberman, 2005). A DT can be used to visually and explicitly represent decisions for decision support. In data mining and machine learning, a DT is a predictive model (Teorey, 1999; Flamig, 2000; 
Witten and Frank, 2000). The DT describes data but not decisions for the resulting classification tree as an input for decision-making. With a graphical representation, a DT model maps from observations about an item to the conclusions about its target value. In the structure of the tree, leaves represent classifications and branches represent conjunctions of features that lead to those classifications. The machine learning technique for inducing a decision tree from data is called decision tree learning, or (colloquially) decision trees. Using DTs large amounts of data can be analyzed in a relatively short time for real-time applications (Abraham et al., 2007).

\section{Applications of soft computing in agricultural and biological engineering}

With the theoretical developments of soft computing, a large variety of successful applications to many industrial systems have been created. During the last decade, interest of applying soft computing techniques to systems in agricultural and biological engineering has been growing greatly. As in other fields, soft computing plays an especially important role in providing techniques to integrate human-like vagueness and real-life uncertainty into conventional computing programs. Problems in soil and water, crop management and post harvesting, precision agriculture, food processing, food quality and safety, and agricultural vehicle and robotics have been solved through soft computing-based classification, modeling and prediction, and optimization and control. This paper reviews significant papers for each of these agriculturerelated areas, organized by the soft computing technique utilized.

\subsection{Fuzzy logic applications}

\subsubsection{Overview}

In summary of 136 related papers and reports, FL has been applied in solving problems in crop management (17\%), soil and water (16\%), food quality and safety (14\%), animal health and behavior (10\%), agricultural vehicle control (8\%), precision agriculture $(7 \%)$, greenhouse control (7\%), agricultural machinery (4\%), food processing (4\%), air quality and pollution (3\%), agricultural facilities (2\%), agricultural robotics (1\%), chemical application (1\%), and others (6\%) such as natural resources management and agricultural product design. These applications have been created through FL mainly by control (28\%), modeling and prediction (24\%), classification (24\%), fuzzy clustering (9\%), rule-based inference (7\%), multisensor data fusion (4\%), optimization (1\%) and others (3\%) such as thresholding and pattern inference.

\subsubsection{Crop management}

For crop pest management, Pydipati et al. (2005) used the color co-occurrence method for textural analysis to determine whether classification algorithms could be used to identify diseased and normal citrus leaves. One of the classification strategies investigated was ANN classifiers based on the RBF (Radial Basis Function) networks with fuzzy outputs that indicate a measure of strength. The level of fuzziness was determined by setting any value $<0.5$ as equivalent to 0 , and any value $>0.5$ as equivalent to 1 . This is a typical way of dealing with the output of classifier using FL, which helps decide the output class labeling with the output of decimal numbers.

Yang et al. (2000a, 2003) reported on development of an image capture/processing system to detect weeds and a fuzzy logic decision-making system to determine where and how much herbicide to apply in an agricultural field. As information concerning economic thresholds of weed impact on crop productivity cannot easily be adapted to a given region or even to a given farm, a fuzzy logic approach was applied to convert image data into sprayer commands to allow farmers to use experience to classify weed status at a given location in the field. This research indicated that a fuzzy logic system is able to understand and facilitates the representation and processing of human knowledge in computer and the inputs, outputs, and rules of FL are easy to modify.

\subsubsection{Irrigation and ET calculation}

For irrigation scheduling, Odhiambo et al. (2001a) examined FL for estimating daily reference evapotranspiration (ET) with fewer parameters compared with the standard FAO (Food and Agriculture Organization) Penman-Monteith method, which is sophisticated and requires several input parameters some of which have no actual measurements but are estimated from measured weather parameters. In this study, two fuzzy ET models were developed to estimate reference grass ET, using two and three weather parameters, respectively. The results illustrated that the fuzzy ET models could yield accurate estimation of ET.

Al-Faraj et al. (2001) developed a rule-based FL crop water stress index (CWSI) using growth chamber data and tested this method on tall fescue canopies grown in a greenhouse. The upper and lower theoretical CWSI baselines may shift according to net radiation, wind, and stomatal resistance. This study proposed fuzzy logic to develop a FL-CWSI system to overcome the uncertainty of baseline. The FL-CWSI system has just three inputs: canopy-air temperature differential, vapor pressure deficit, and shortwave radiation, and one output: CWSI. To calculate the crop water stress index under different levels of solar radiation and vapor pressure deficit, 150 fuzzy rules were established to relate the system inputs and the output. The use of FL-CWSI eliminated the need to calculate or calibrate empirical or theoretical base line limits. The FL-CWSI was successfully tested using independent greenhouse data.

Thomson and Ross developed a coupled sensor- and modelbased irrigation scheduling method (Thomson et al., 1993; Thomson and Ross, 1996). Based on this work Thomson (1998) described a concept by which readings from sensors could be used to reparameterize or adjust inputs to a crop simulation model. Readings from sensors and the modeled results were used synergistically in an adaptive learning scheme.

\subsubsection{Soil analysis}

Soil mapping using FL has been reported by Zhu et al. (2001), Bragato (2004), Shi et al. (2004), Qi et al. (2006), and Zhu et al. (in press). Lark (2000) illustrated how to design sampling grids from imprecise information on soil variability with an approach based on the fuzzy kriging variance. This approach can derive a fuzzy set of grid spacings that will achieve a target kriging variance when given a fuzzy formulation of the soil property variogram. This fuzzy set of grid spacings can then be defuzzified in a more or less conservative way to define a sampling scheme. In support of precision agriculture, Van Alphen and Stoorvogel (2000) developed a functional approach to soil characterization involved in water stress, nitratestress, nitrate-leaching and residual nitrogen-content at harvest for a precision agriculture decision support system. In the study, a fuzzy c-means classifier was used to group the soil profiles into functional classes. Ferguson et al. (2003) evaluated approaches for site-specific use of the nitrification inhibitor based on slope and surface texture for management zone definition. In this study, fuzzy cluster analysis was demonstrated the potential to define management zones for use of nitrification inhibitors from easily obtained spatial yield or soil $\mathrm{EC}_{\mathrm{a}}$, rather than expensive grid sampling of soil chemical and physical properties.

\subsubsection{Precision agriculture}

Ortiz et al. (2008) used fuzzy clustering of elevation and slope of the terrain to delineate root knot nematode (RKN) risk zones for a comparison test of two nematicide application rates on nematode population density and cotton lint yield. The results from this 
study clearly showed that RKN control and final yield varied with respect to the nematicide type and rate across risk management zones based on fuzzy clustering of terrain elevation and slope, normalized difference vegetation index (NDVI) of bare soil reflectance, and apparent soil electrical conductivity.

Xiang and Tian (2007) used fuzzy inference in an ANN framework to develop an artificially intelligent controller that automatically adjusts multispectral camera parameters, such as "gain" and "exposure time" to compensate for changing natural lighting conditions and to acquire white-balanced images. The artificial intelligence control algorithm did require no mathematical model of the system, and provided better control performance compared to conventional control methods.

Jones and Barnes (2000) described precision crop management as a multi-objective decision-making process that must incorporate a diversity of data, opinion, preference and objective. This paper developed fuzzy composite programming, a distance-based multi-objective optimization problem that uses fuzzy representation of uncertainty to combine remote sensing and crop models for decision support in precision crop management. This approach allows users to express individual or corporate values and preferences; highlights the degree of imprecision associated with each information source used (i.e. model accuracy, uncertainty in costs and returns, etc.); highlights the degree of imprecision associated with each alternative; facilitates structuring of the decision process; reduces several levels of complex information into a single chart; allows examination of trade-off between alternatives and interests; and forces examination of inter-relationships between interests.

Ambuel et al. (1994) successfully developed and used a fuzzy logic yield simulator. Two expert system models were developed using FL rules. In one model chemical and physical characteristics of the soil were measured and combined with local meteorological data as input parameters. In the other model soil properties were estimated rather than measured. Model predicted yields were then compared with measured yields for those fields. The results indicate that on a relative basis, predicted yields generally agreed with measured yields.

\subsubsection{Chemical application}

Gil et al. (2008) used linear multiple regression and FL inference models to evaluate the effects of micrometeorological conditions on pesticide application for two spray qualities (fine and very fine). Spray losses were predicted using fuzzy inference systems. Interpretable rules were established for the characterization of micrometeorological parameters using the two sprays. Q. Chen et al. (2006) and Y. Chen et al. (2006) developed an intelligent pesticide spray system based on fuzzy control and machine vision to perform site-specific pesticide application. Cho and Ki (1999) developed a FL controller for autonomous operation of a speed sprayer in an orchard. The operation of the controller was graphically simulated under the real condition of the orchard. Machine vision was also used to determine vehicle heading and four ultrasonic sensors were used to detect obstacles during the operation.

\subsection{Artificial neural network applications}

\subsubsection{Overview}

ANNs have the largest body of applications in agricultural and biological engineering when compared with other soft computing techniques. In summary of related 348 papers and reports, ANNs have been applied in solving problems in food quality and safety (35.34\%), crop (22.7\%), soil and water (14.37\%), precision agriculture (6.61\%), animal management (5.17\%), post harvest (2.59\%), food processing (2.3\%), greenhouse control (2.01\%), agricultural vehicle control (1.15\%), agricultural machinery (1.15\%), agricultural pollution (1.15\%), agricultural biology (1.15\%), ecology and natural resources (1.44\%), agricultural robotics $(0.29 \%)$, chemical application (0.29\%), and others (2.3\%) such as bioenergy and agricultural facilities. These ANN applications have been created mainly through classification (45.11\%), modeling and prediction (43.97\%), control (4.02\%), and simulation (2.59\%), parameter estimation (2.01\%), detection (1.15\%), data clustering (0.57\%), optimization (0.29\%) and data fusion (0.29\%) as well.

Similar to applications in general engineering fields, most works in agricultural and biological engineering have been accomplished using a multilayer feedforward ANN trained by the famous BP algorithm, which was inspired by the work of Rumelhart et al. (1986a, 1986b). Among 348 collected papers and reports 210 were based on multilayer feedforward neural networks trained by the BP algorithm and 83 did not explicitly state ANNs' structure and training algorithm. Of the remainder twelve were based on PNN (Probabilistic Neural Network); eleven were based on MLP (Multi Layer Perceptron) using different training algorithms such as Levenberg-Marquardt optimization procedure, Broyden-Fletcher-Goldfarb-Shanno (BFGS) optimization procedure, and GA; seven were based on Kohonen SOM (Self Organizing Map), which is a popular unsupervised training algorithm; six were based upon other unsupervised training algorithms such as fuzzy ART (Carpenter et al., 1991), ART2 (Carpenter and Grossberg, 1987), and Auto-Associative network (Anderson et al., 1977); four were based on RBF, which is a neural network good for function approximation; three were based on LVQ (Learning Vector Quantization); two were based on GRNN (Generalized Regression Neural Network). Finally ten were based on other network structures such as Counter-Propagation (CP), and Adaptive Logic Network (ALN).

\subsubsection{Crop management}

In a crop field study, Meyer et al. (2004) conducted a digital camera operation study for classifying uniform images of grass, bare soil, corn stalks residue, and wheat straw residue using a barium sulfate reference panel based on color. The classifications were conducted with a combination of least-squares estimation and BP training to generate a fuzzy inference system. Fuzzy input variables included RGB or HSI average values alone, with and without monochromatic light sources, and with and without luminance and background light source color temperature measurements for each fuzzy inference model. The ANN system provided a tool for evaluating digital camera operating performance by setting up a simple class, supervised learning system for plant, soil residue color images.

In order to develop a multi-spectral optical system for remote sensing of nitrogen content of crops, Chen et al. (2007) determined significant wavelengths in image data for estimating nitrogen content of cabbage seedling leaves by stepwise multi-linear regression analysis. A feedforward ANN model with cross-learning scheme was further developed to increase prediction accuracy. The results indicated that the ANN model with cross-learning using spectral information at $490,570,600$, and $680 \mathrm{~nm}$ could be used to develop a practical remote sensing system to predict nitrogen content of cabbage seedlings.

Sui and Thomasson (2006) developed a BP trained feedforward ANN to predict nitrogen status in cotton plants based on data from a ground-based sensing system. The system consists of a multi-spectral optical sensor for plant canopy sensing, an ultrasonic sensor for plant height measurement, and a data-acquisition and processing unit. Field tests of the system over 2 years involved measuring spectral reflectance and plant height simultaneously in real time in situ. Results showed that the neural networks were able to predict nitrogen status of the cotton plants at $90 \%$ accuracy with two categories: deficiency and non-deficiency. 
Karimi et al. (2005) evaluated discriminant analysis as a tool for classifying images with respect to the nitrogen and weed management practices applied to the experimental plots, and compared the classification accuracy of this technique with those obtained by ANN and DT algorithms on the same data. For identifying weed and nitrogen stresses in corn, the discriminant analysis was found to provide the best classification accuracy at the early growth stage, whereas better accuracy was obtained with ANN models at the tasseling and full maturity stages.

Tumbo et al. (2002b) used an on-the-go system for sensing chlorophyll status in corn using BP trained feedforward ANNs and fiber-optic spectrometry to acquire spectral response pattern data in corn fields. The neural network model incorporated into the mobile system was trained using statically collected plantcenter spectral data and chlorophyll readings acquired by SPAD 502 chlorophyll meter on the some day and in the same field plots. The neural network model showed good correlation between predicted and actual chlorophyll readings of the calibration data set.

Goel et al. (2001) compared the DT method and ANN method to classify nitrogen stress within a corn field based on hyperspectral images. Goel et al. (2003) also evaluated the DT and ANN classification algorithms for the classification of hyperspectral data to discriminate between different growth scenarios in a corn field to identify weed stress and nitrogen status of corn. In both studies, the ANNs obtained slightly better results than the DTs.

Tang et al. (2003) developed a texture-based weed classification method consisting of a low-level Gabor wavelets-based feature extraction algorithm and a high-level ANN-based pattern recognition algorithm. In this research, three species of broadleaf weeds (common cocklebur, velvetleaf, and ivyleaf morning glory) and two graces, giant foxtail and crabgrass, which are common in Illinois, were studied. After processing 40 sample images with 20 samples from each class, the results showed that the method was capable of classifying all the samples correctly with high computational efficiency, demonstrating its potential for practical implementation under real-time constraints.

Cho et al. (2002) used an ANN using a regularization method to overcome overfitting with better generalization for distinguishing radish from weeds effectively. In this study, a machine vision system using a charge coupled device camera for the weed detection in a radish farm was developed. Shape features were analyzed with the binary images obtained from color images of radish and weeds. Using the discriminant analysis, the successful recognition rate was $92 \%$ for radish and $98 \%$ for weeds. To recognize radish and weeds more effectively, an ANN was used. The ANN model distinguished the radish from the weeds with $100 \%$.

Yang et al. (2002) developed a weed recognition imaging system based on LVQ networks to assist in the precision application of herbicides in corn fields. Digital images were collected and the intensities of the colors were compared for each pixel of the images. The pixel intensities of the images were used as the inputs for LVQ ANNs. The ANNs were trained to distinguish corn from weeds, as well as to differentiate between weed species. The success rate for a single ANN in distinguishing a given weed species from corn was as high as $90 \%$, and as high as $80 \%$ in distinguishing any of four weed species from corn.

Moshou et al. (2002) used the SOM ANN in a supervised way for a classification task for a weed species spectral detector. The neurons of the SOM become associated with local linear mappings. Error information obtained during training was used in a novel learning algorithm to train the classifier. The proposed method achieved fast convergence and good generalization.

Bajwa and Tian (2001) developed weed density models using a feedforward, BP trained MLP network to map the spatial distribution of weed density based on aerial digital color infrared remote sensing over a soybean field. In this study, the ANN weed density models resulted in $R^{2}$ values of $0.83-0.83$. This model mapped the spatial distribution of weed density with a $R^{2}$ value of 0.58 for a field not used in modeling for model validation.

It is quite difficult to use machine vision to distinguish weeds from the main crop in real time, due to the substantial computational resources and the complicated algorithms required. Yang et al. (2000b) developed ANNs to overcome some of these difficulties by interpreting images quickly and effectively to distinguish young corn plants from weeds. The ANNs were one-hidden-layer feedforward networks trained with the BP algorithm. In the study, a total of 80 images of corn plants and weeds were used for training purposes. For some ANNs, the success rate for classifying corn plants was as high as $100 \%$, whereas the highest success rate for weed recognition was $80 \%$.

Burks et al.(2000) used the color co-occurrence texture statistics as input variables for a BP trained ANN weed classification model. The study evaluated classification accuracy as a function of network topology and training parameter selection. In addition, training cycle requirements and training repeatability were studied.

El-Faki et al. (2000) developed and tested ANN-based weed detection algorithms capable of detecting the leading weed species competing with wheat and soybean crops. This study compared statistical discriminant analysis and two ANN classifiers. These classifiers were trained and tested using three weed species (Johnsongrass, redroot pigweed, and yellow foxtail) with soybean and three weed species (wild buckwheat, cheat, and field bindweed) with wheat. The results showed that the statistical discriminant analysis classifier was more accurate than the ANN classifiers in classification accuracy.

Suzuki et al. (2009) developed a discriminant model for automated weed control using imagery from a line scan hyperspectral imaging sensor. Prior to developing discriminators, explanatory variables for the models were generated from spectral bands using two methods: stepwise selection method (RAW) using the multivariate test statistic Wilks' Lambda and Principal Component Analysis (PCA). Linear Discriminant Analysis (LDA) and a neural network (NN) models were employed for development of the discriminator, resulting in four discriminant models to test: RAW-LDA, RAW-NN, PCA-LDA, and PCA-NN. Accuracies of the NN models were superior to the LDA, but success rates for all discriminant models were greater than $85 \%$. RAW method was superior to PCA for processing speed because PCA selected variables calculated from all wavebands.

In a study of crop leaf area indices, Koller and Upadhyaya (2005a) developed an ANN model that utilized the leaf area index (LAI) values derived from aerial images to train and predict LAI changes on a daily basis. Based on this ANN model, Koller and Upadhyaya (2005b) predicted the processing tomato yield based on soil, crop, and environmental parameters. Koller and Upadhyaya (2005c) further developed a BP trained feedforward ANN model to predict daily LAI values based on six sets of modified NDVI values derived from biweekly aerial images obtained during the tomato growing season. The trained network was able to predict LAI values with $R^{2}$ values of 0.96 or higher. The cumulative LAI predicted by the ANN model correlated well with the measured values $\left(R^{2}=0.83\right)$.

Walthall et al. (2004) compared empirical and ANN approaches for estimating corn and soybean LAI from Landsat ETM+ imagery. In this study, an evaluation of LAI retrieval methods was conducted using (1) empirical methods employing NDVI and a new soil adjusted index that uses green wavelength reflectance, (2) a scaled NDVI approach that uses no calibration measurements, and (3) a hybrid approach that uses an ANN and a radiative transfer model without site-specific calibration measurements. Compared to other methods, the ANN-based approach is computationally complex as multiple analytical steps must be completed before an estimate can be produced. 
In the study of crop disease, Pydipati et al. (2005) used the color co-occurrence method for textural analysis to determine whether classification algorithms could be used to identify diseased and normal citrus leaves based on a Mahalanobis minimum distance classifier as well as ANN classifiers based on the BP algorithm for two-hidden-layer feedforward networks and RBF networks with fuzzy outputs giving a measure of strength. The results indicated that that the Mahalanobis classifier and the BP trained ANN classifier performed equally well when using hue and saturation texture features selected through a stepwise variable reduction method.

In a study of crop growth, Hsieh et al. (2001) adopted a dualhidden-layer feedforward ANN trained with the error BP algorithm to analyze experimental data and develop strategies for a dynamic growth model to simulate the relationship between environmental factors (temperature, water supply and daily radiation) and cabbage seedling quality. Hsieh et al. (2003) continued to work on the model development of a BP trained, multilayer feedforward ANN model to investigate the relationship between the quality of cabbage seedlings and their growth environment. This study developed and evaluated three different ANN models. By integration of schemes for various growth stages and the historical growth factor, the model contributes markedly in prediction ability. The error is decreased by $77 \%$ when the best model developed in this work was used.

Tumbo et al. (2002a) trained a single-hidden-layer feedforward ANN using the BP algorithm using spectral channels of the hyperspectral reflectance response patterns from corn plant as inputs for predicting chlorophyll values as the output. The BP trained ANN model was developed using spectral channels of the spectral reflectance response patterns as inputs and chlorophyll readings as an output. The model showed strong correlation between predicted and actual chlorophyll meter readings from the same corn variety and soil type as the training set.

Moshou et al. (2001) used the SOM ANN in a supervised way for classification of agricultural plants. The classification method was applied in a precision farming application for classification of crops and weeds using spectral properties. The classification performance of the proposed method was proven to be superior compared with other statistical and neural classifiers, such as an optimal Bayesian classifier in the form of a probabilistic neural network.

\subsubsection{Irrigation and ET calculation}

Elgaali et al. (2006) developed a one-hidden-layer feedforward ANN model and a consumptive use model for the region of Colorado's Arkansas River basin to investigate the possible effects of regional climatic changes on irrigation water supply and demand. The two models were applied to the region to estimate the effects of climate change on irrigation water balance.

For selection of the best compromise irrigation planning strategy in the case study of Jayakwadi irrigation project, Maharashtra, India, Raju et al. (2006), based multiobjective linear programming optimization, employed Kohonen neural networks to sort nondominated irrigation planning strategies into smaller groups. The results indicated that the integrated model methodology was effective for modeling multiobjective irrigation planning problems.

In ET calculation, Bruton et al. (2000) developed feedforward ANN models trained with the BP algorithm to estimate daily pan evaporation using measured weather variables as inputs from weather data of Rome, Plains, and Watkinsville, Georgia, USA. In this study, daily pan evaporation was also estimated using multiple linear regression and the Priestley-Taylor method and was compared to the results of the ANN models. The ANN model of daily pan evaporation with all available variables as inputs was the most accurate model. In overall, pan evaporation estimated with ANN models was slightly more accurate than pan evaporation estimated with a multiple linear regression model or the Priestley-Taylor equation.
Odhiambo et al. (2001b) developed a feedforward ANN on a conceptual and structural basis in a study on elimination of trialand-error in determining the shape of the membership functions in the fuzzy control rules for estimating daily reference ET. The results of the study showed that the optimized fuzzy-neural model is reasonably accurate, and is comparable to the FAO Penman-Monteith equation. This approach can provide an easy and efficient means of tuning fuzzy ET models.

\subsubsection{Soil analysis}

In the study of soil profiles, Odhiambo et al. (2004) presented an application of a fuzzy-neural network classifier for unsupervised clustering and classification of soil profiles using ground-penetrating radar imagery. Freeland and Odhiambo (2007) used a two-layer perceptron neural network that performs supervised classification to examine the feasibility of using textural features extracted from ground-penetrating radar for nonintrusively mapping subsurface soil conditions. The ANN classifier was used to assign data to the known subsurface categories. The results of subsurface characterization using extracted textural features were found to be in close agreement with results obtained by careful visual interpretation of the data. This approach of groundpenetrating radar imagery classification was to be considered as an alternative method to traditional human interpretation only in the classification of voluminous data sets, wherein the extensive time requirement would make the traditional human interpretation impractical.

Bajwa et al. (2004) used a multilayer feedforward ANN trained with GA to optimize the ANN topology and other four unsupervised and supervised methods to identify aerial hyperspectral image bands to characterize soil electrical conductivity and canopy coverage in agricultural fields. Band selection was performed with both unsupervised and supervised approaches. Five methods (three unsupervised and two supervised) are proposed and compared to identify hyperspectral image bands to characterize soil electrical conductivity and canopy coverage in agricultural fields. Each hyperspectral image band was ranked using all five methods and ANN measure was the most useful in selecting bands specific to a target characteristic with minimum information redundancy.

Ferentinos and Albright (2002) presented a feedforward ANN model that was trained with the quasi-Newton BP algorithm and predicts $\mathrm{pH}$ and electrical conductivity changes in the root zone of lettuce grown in a deep-trough hydroponic system. The most suitable and accurate combination of network architecture and training method was one hidden layer with nine hidden nodes, trained with the quasi-Newton backpropagation algorithm. The model proved capable of predicting $\mathrm{pH}$ at the next 20 -min time step within 0.01 $\mathrm{pH}$ units and electrical conductivity within $5 \mu \mathrm{S} \mathrm{cm}^{-1}$. Simpler prediction methods, such as linear extrapolation and the lazy man prediction (in which prediction is the value of the previous time step), gave comparable accuracy much of the time. However, they performed poorly in situations where the control actions of the system had been activated and produced relatively rapid changes in the predicted parameters. In those cases, the neural network model did not encounter any difficulties predicting the rapid changes.

Additionally, Fidêncio et al. (2001) applied CP ANN and RBF ANN in classification of soils using near-infrared spectroscopy. Ingleby and Crowe (2001) developed feedforward ANN models with a reduced-memory Levenberg-Marquardt BP training algorithm for predicting organic matter content in Saskatchewan soils. Altendorf et al. (1999) developed a set of feedforward ANNs with BP training to predict soil water content at a given depth as a function of soil temperature.

In the study of soil properties, Zhang and Kushwaha (1999) applied ANNs to simulate the interaction between soil and tool for tillage and soil behavior. Schaap et al. (1998) calibrated hierarchical 
ANN models for prediction of water retention parameters and saturated hydraulic conductivity from basic soil properties.

In the studies of soil temperature, Yang et al. (1997a) developed a model based on a feedforward ANN training with the BP algorithm to simulate daily soil temperatures at 100,500 and $1500 \mathrm{~mm}$ depths of soil from Ottawa, Ontario, Canada. Yang et al. (2004b) compared a multivariate adaptive regression splines model with feedforward ANNs in simulation of soil temperature at different depths. The correlation coefficients of linear regression from both multivariate adaptive regression splines and ANNs were always higher than 0.950 . The results demonstrate the potential of multivariate adaptive regression splines to be used as a regression technology in agricultural applications.

A number of papers developing and using ANNs have been published for soil property studies in Geoderma and SSSAJ in recent years. Anagu et al. (2009) developed sorption models as a function of basic soil properties using ANNs for estimation heavy metal sorption in German soils. The results of the study indicated that the ANN models performed better than on multiple linear regression MLR in all cases for 9 heavy metals using 13 soil properties as well as solution phase concentrations as inputs and sorbed phase concentrations as output. Khalilmoghadam et al. (2009) used ANNs in estimating soil shear strength from measured particle size distribution, topographic attributes, NDVI, soil organic carbon (SOC), and $\mathrm{CaCO}_{3}$. Three neural networks structures: multilayer perceptron (MLP), generalized feedforward, and modular feedforward networks were used and compared with conventional multiple-linear regression analysis. In the comparison the improvements were identified with all three neural network models over a conventional MLR models. Cockx et al. (2009) evaluated ANNs for extraction of topsoil textural information from the depth-weighted EM38DD (an electromagnetic induction soil sensor) signals to predict the topsoil clay content. Earlier Merdun et al. (2006) compared ANN and regression pedotransfer functions for prediction of soil water retention and saturated hydraulic conductivity and demonstrated that ANN produced promising results.

\subsubsection{Precision agriculture}

Xiang and Tian (2007) developed a BP trained one-hidden-layer feedforward ANN in an artificially intelligent controller for gain and exposure time automation of a multispectral camera to compensate for changing natural lighting conditions and to acquire white-balanced images. This study was undertaken to develop an artificially intelligent controller based on an ANN with an adaptive neuro-fuzzy inference system. It was shown through experiments that the developed algorithm was able to complete multispectral camera parameter control within three iterations for each channel. The convergence speed was faster than with conventional control methods.

Irmak et al. (2006) developed a BP ANN model to predict the spatial distribution of soybean yields and to understand the causes of yield variability. First, a BP trained ANN model was developed by relating soybean yield to topography, soil, weather, and site factors and the model predictions were evaluated for the same field for independent years. Then, the potential use of the ANN model was also explored for predicting yields in independent fields. Finally, the ability of the ANN to attribute yield losses due to soybean cyst nematodes ( $\mathrm{SCN}$ ), soil $\mathrm{pH}$, and weeds was evaluated. The results showed that the ANN model could predict spatial yield variability well.

Miao et al. (2006) employed ANN analysis to evaluate the relative importance of selected soil, landscape and seed hybrid factors on corn yield and grain quality in two Illinois, USA fields. The results indicated that the response curves generated by the ANN models were more informative than simple correlation coefficients or coefficients in multiple regression equations. Uno et al.
(2005) developed yield prediction models using statistical and ANN approaches along with various vegetation indices. The models were used to predict corn yield from compact airborne spectrographic imager data. The study showed that although no clear difference was observed between ANNs and stepwise multiple linear regression models, the high potential usefulness of ANNs was confirmed. Drummond et al. (2003) investigated supervised feedforward ANNs along with stepwise multiple linear regression and projection pursuit regression to identify methods able to relate soil properties and grain yields on a point-by-point basis within ten individual siteyears. In the study, the ANNs consistently outperformed stepwise multiple linear regression and projection pursuit regression and provided minimal prediction errors in every site-year. However, in site-years with relatively fewer observations and in site-years where a single, overriding factor was not apparent, the improvements achieved by neural networks over stepwise multiple linear regression and projection pursuit regression were small.

Liu et al. (2001) designed a fully connected, BP trained feedforward ANN to approximate the nonlinear yield function relating corn yield to factors influencing yield. Factors affecting crop yields, such as soil, weather, and management, were so complex that traditional statistics couldnot give accurate results. As an automatic learning tool, the ANN is an attractive alternative for processing the massive data set generated by precision farming production and research. In this study, a feedforward, completely connected, back-propagation ANN was designed to approximate the nonlinear yield function relating corn yield to factors influencing yield.

\subsubsection{Chemical application}

Krishnaswamy and Krishnan (2002) predicted the nozzle wear rates for four fan nozzles using regression and ANN techniques. A comparison of the regression model and ANN model showed that the regression and the neural network models performed equally well for the predictions. Yang et al. (1997b) used feedforward ANNs for simulation of pesticide concentrations in agricultural soils. An ANN model can be executed in real-time, while the sprayer is working in the field, in order to adjust application rates to the real extent of the problem. In this study, an ANN model was built and trained with inputs of: accumulated daily rainfall, soil temperature, potential ET, as well as tillage practices and the number of days elapsed after pesticide application.

\subsection{Genetic algorithm applications}

\subsubsection{Overview}

Based on a summary of 83 papers and reports, GAs have been applied in solving problems in crop management (31\%), water management (27\%), food quality and safety (11\%), food processing (6\%), precision agriculture (4\%), agricultural biology (4\%), agricultural machinery (2\%), agricultural facilities (2\%), animal behavior $(2 \%)$, and others (11\%) such as agricultural vehicle, robotics, and pollution. GAs are basically an optimization and search method. The applications for optimization take the largest portion of the total, $66 \%$. GAs have been also used to assist with modeling and prediction (18\%), classification (12\%), control (2\%), data clustering (1\%) and value thresholding (1\%).

\subsubsection{Crop management}

Thorp et al. (2004) used the GA-based image segmentation algorithm (Tang et al., 2000) to generate measurements of percent vegetation cover from the hyperspectral images collected over a soybean field. Fang et al. (2003) estimated crop leaf area index by integrating a canopy radiative transfer model and the GA optimization technique. This method was used to retrieve leaf area index from field measured reflectance as well as from atmospherically corrected Landsat ETM+ data. Yao and Tian (2003) proposed and 
tested a GA-based selective principal component analysis method using hyperspectral remote sensing data and ground reference data collected within a corn field for chlorophyll content, plant population, and various hybrids. The GA-based method was used to select a subset of the original image bands, which could reduce the data dimension. A principal component transform was subsequently applied to the selected bands. Then, image processing on the reduced feature space could be performed with improved accuracy. Tang et al. (2000) developed a machine vision-based weed detection technology under outdoor natural lighting conditions. In image processing, a GA-based, supervised color image segmentation method in the hue-saturation-intensity color space was used to separate plants (crop and weeds) from the background (soil, rocks, and residue) for this real-time, machine-vision-based, in-field variability mapping and selective herbicide application system. Pabico et al. (1999) presented a conceptual framework for using a GA to determine cultivar coefficients of crop simulation models.

In a study of weed distribution in crop fields, Diaz et al. (2005) presented a method for inducing a model that appropriately predicts the heterogeneous distribution of wild-oat in terms of some environmental variables. From several experiments, distinct rule sets have been found by applying a GA to carry out the automatic learning process. The rule set extracted was able to explain about most of weed variability. Noguchi et al. (1998) developed an intelligent vision system for autonomous vehicle field operations. Fuzzy logic was used to classify the crops and weeds. A GA was used to optimize and tune the fuzzy logic membership rules.

\subsubsection{Irrigation}

Raju and Kumar (2004) presented an application of GA for irrigation planning. The GA technique was used to evolve efficient cropping patterns to maximize benefits for an irrigation project in India. Kumar et al. (2006) presented a GA model for obtaining an optimal operating policy and optimal crop water allocations from an irrigation reservoir. The model was applied to the Malaprabha single-purpose irrigation reservoir in Karnataka State, India. The optimal operating policy obtained using the GAs is similar to that obtained by linear programming.

Wardlaw and Bhaktikul (2004) described the development of a GA to solve an irrigation water scheduling problem. The implementation of the GA was to optimize the utilization of water resources in irrigation systems operating on a rotational basis along with constraints that relate to field soil moisture balances as well as canal capacities. Cai et al. (2001) described strategies for solving large nonlinear water resources models management with a combination of GAs with linear programming.

Kuo et al. (2000) presented a model based on on-farm irrigation scheduling and a simple GA optimization method for decision support in irrigation project planning. The proposed model was applied to an irrigation project located in Delta, Utah for optimizing economic profits, simulating the water demand, crop yields, and estimating the related crop area percentages with specified water supply and planted area constraints. Simulation results demonstrated that the most appropriate parameters of GAs for this study were: number of generations, population sizes, probability of crossover, and probability of mutation.

\subsubsection{Soil analysis}

Pachepsky and Acock (1998) developed stochastic imaging of the available soil water capacity (AWC) and a soybean crop model GLYCIM to simulate variability and uncertainty in crop yield estimates as related to soil sampling density and weather patterns using GAs. Parasuraman et al. (2007) estimated saturated hydraulic conductivity using genetic programming (GP), tree-like representations of Gas solution domain. In the study the performance of the GP models were compared with the ANN models and GP appeared to be a promising tool for estimating the saturated hydraulic conductivity.

\subsubsection{Precision agriculture}

Liu et al. (2001) optimized fifteen input factors with a GA to determine maximum yield after the ANN was trained. The ANN approximated the nonlinear yield function relating corn yield to factors influencing yield, was trained.

\subsubsection{Chemical application}

Potter et al. (2000) used GA to optimize nozzle type or release height using a desired deposition as model input with a model constrain on other factors such as aircraft type and spray system for aerial pesticide application optimization.

\subsection{Bayesian inference applications}

\subsubsection{Overview}

Based on a study of 46 papers and reports, BI has been applied in solving problems in crop management (28\%), food quality and safety (28\%), water management (17\%), food processing (7\%), precision agriculture (7\%), and others (13\%) such as bioenergy and animal health. BI is basically a classifier for pattern recognition. The applications for classification total $50 \%$. BI also has been used to help modeling and prediction (35\%), parameter estimation (11\%), and optimization and control (4\%).

\subsubsection{Crop management}

In weed detection, Mathanker et al. (2007) used a Bayesian classifier for classifications using shape, color, spectral image features. The classifier conducted three classifications using only shape features, only green color and spectral energy features, and all features combined. The classification accuracy using these features at different resolutions for weed detection varied from $80 \%$ to $87 \%$. The performance was unaffected by image resolution and shows potential for field applications.

For outdoor field plant detection, Tian and Slaughter (1998) developed an environmentally adaptive segmentation algorithm. The results of the environmentally adaptive segmentation algorithm were used to create a Bayesian classifier as decision surface. Marchant and Onyango (2003) compared a Bayesian classifier with a multilayer feedforward ANN for plant/weed/soil discrimination in color images with a preference of Bayesian classifier over ANN in this case.

\subsubsection{Irrigation and ET calculation}

Clemmens and Keats (1992) applied BI to the real-time feedback control of a basin irrigation system. Bayesian inference is applied to the real-time feedback control of a basin irrigation system. Estimates of the Kostiakov $k$ (infiltration parameter) and Manning $n$ (Roughness parameter) were obtained during water advance so that the optimum cutoff time can be determined from: (1) estimates from observation of advance time and distance and solution of the zero-inertia border irrigation model; and (2) either historical estimates of parameters or subjective estimates made by the irrigator. The study showed that the BI has some potential for improving real-time control of surface irrigation systems.

Sayde et al. (2008) proposed an analytical method to reduce uncertainty in determination of soil water depletion by incorporating estimates of the uncertainties of ET and measured soil moisture into the analysis. Using a Bayesian analysis the probability distributions of the two estimators were incorporated into a posteriori probability distribution of depletion that provides a better basis for irrigation decisions. 


\subsubsection{Precision agriculture}

Chinchuluun et al. (2007) developed a robust Bayesian classifier with normal distribution for color segmentation in a citrus yield mapping system on a canopy shake and catch harvester. The Bayesian classifier worked relatively well on the non-uniform images.

\subsubsection{Chemical application}

Lee and Slaughter (1999) used Bayesian classifiers in development of a real-time intelligent robotic weed control system for selective herbicide application to in-row weeds using machine vision and precision chemical application.

\subsection{Decision tree applications}

\subsubsection{Overview}

A summary of 31 papers and reports on DT applications indicates that DT have been applied in solving problems in crop management (26\%), agricultural safety (16\%), animal production and management (13\%), food safety (13\%), water (13\%), agricultural pollution (6\%), and others (13\%) such as precision agriculture and biological control. DT also is a classifier. The applications for classification account for $52 \%$ of the total. DT has been also used to conduct alternative induction (23\%), rule representation (13\%), pattern induction (6\%), and others (6\%) such as function approximation and control.

\subsubsection{Crop management}

Karimi et al. (2005) compared discriminant analysis, ANN and DT for classifying images with respect to the nitrogen and weed management practices applied to the experimental plots. For identifying weed and nitrogen stresses in corn, DT could not compete with the discriminant analysis and ANN for better results. Yang et al. (2004a) used DTs to classify multispectral images of experimental plots having different crop and weed populations. DTs are directly suited to classification since data representing a given individual are sorted through the decision tree structure to fall directly into a pre-defined category. In this study, an aircraft-mounted pushbroom imaging spectrometer was used to obtain scans of the plots in one blue, five green, five red, and thirteen infrared bands. Three types of input were: absolute values of radiance from the 24 wavebands, vegetation index (VI), which consists of 12 inputs, and NDVI which consists of 65 inputs. Results showed that the most complex classification problem (distinguishing between $11 \mathrm{crop} /$ weed combinations) was best resolved using the NDVI inputs.

Goel et al. (2001) used a DT method to classify nitrogen stress within a corn field based on hyperspectral images. Goel et al. (2003) compared the DT and ANN classification algorithms for the classification of hyperspectral data to discriminate between different growth scenarios in a corn field to identify weed stress and nitrogen status of corn. DT technology was applied to classify different treatments based on the hyperspectral data. Various tree-growing mechanisms were used to improve the accuracy of classification. Misclassification rates of detecting all the combinations of different nitrogen and weed categories were 43,32 , and $40 \%$ for hyperspectral data sets obtained at the initial growth, the tasseling and the full maturity stages, respectively. However, satisfactory classification results were obtained when one factor (nitrogen or weed) was considered at a time. In this case, misclassification rates were only 22 and $18 \%$ for nitrogen and weeds, respectively, for the data obtained at the tasseling stage.

\subsubsection{Precision agriculture}

Cohen et al. (2006) used the DT method for developing a spatial decision support system (SDSS) for Medfly (the Mediterranean fruit fly) control on fruit crops in Israel. This study established the main steps to assist the coordinators in the decision-making procedure in the development of the SDSS. The output is a map that classifies the citrus plots into one of the following blocks: spraying; spraying is recommended; spraying is not recommended; no-spraying; no data.

Yang et al. (2001) used the DT algorithm to distinguish between manure and chemical fertilizer treatments for airborne hyperspectral imagery classification of agricultural fields. The success of the classification rate was as high as $91 \%$ for the early planting season, $99 \%$ for the mid planting season, and $95 \%$ for the late planting season.

\subsubsection{Chemical application}

Murray et al. (2005) used the DT model to model annual pasture production for analysis of potential of utilizing variable rate application technology from aircraft for improved placement of fertilizer.

\section{Fusion of soft computing methods in agricultural and biological engineering}

With the development of soft computing in agricultural and biological engineering, techniques have integrated different soft computing techniques in a synergistic way. It is advantageous to employ ANNs, fuzzy systems, and evolutionary algorithms in combination instead of exclusively (Hoffmann et al., 2005).

Table 1 lists papers and reports on fusion of soft computing techniques agricultural and biological engineering applications. The list indicates that the integration of FL and ANNs is probably the most common method of fusion in soft computing (thirteen out of twenty-nine collected papers and reports). ANFIS (AdaptiveNetwork-based Fuzzy Inference System) is a fuzzy inference system implemented in the framework of adaptive neural networks (Jang, 1993). By using a hybrid learning procedure, the ANFIS can construct an input-output mapping based on both human knowledge (in the form of fuzzy 'If-Then' rules) and stipulated input-output data pairs. It has been developed and used to solve problems in agricultural and biological engineering.

\subsection{Crop management}

For crop protection, Pearson and Wicklow (2006) developed a neural network to identify fungal species that infect single kernels using principal components of the reflectance spectra as input features. The neural network was trained using GAs as Lestander et al. (2003) indicated that the GA training algorithm method was much less likely to overfit the data.

Meyer et al. (2004) used fuzzy inference systems built with subtractive clustering in an ANFIS for a digital camera operation study for color-based classifications of uniform images of grass, bare soil, corn stalks residue, and wheat straw residue. For weed detection, Neto et al. (2003) used ANFIS for image processing to separate weed from background. A GA was incorporated to adjust the fuzzy membership functions to reduce misclassification and improve image segmentation.

\subsection{ET calculation}

Based on the previous research on fuzzy ET models (Odhiambo et al., 2001a), Odhiambo et al. (2001b) further studied how to eliminate trial-and error in determining the shape of the membership functions in the fuzzy control rules for estimating daily reference ET by application of a fuzzy-neural system through fusing fuzzy logic and ANN on a conceptual and structural basis. The neural component provided supervised learning capabilities for optimizing the membership functions and extracting fuzzy rules from a set 
Table 1

Papers and reports on fusion of soft computing techniques in agricultural and biological engineering.

\begin{tabular}{|c|c|c|c|}
\hline Year & Author & Fusion type & Application area \\
\hline 1992 & Linko et al. & ANN modeling for fuzzy control & Extrusion control \\
\hline 1997 & Kim and Cho & ANN modeling plus fuzzy control simulation & Bread baking process control \\
\hline 1997 & Morimoto et al. & $\begin{array}{l}\text { ANN modeling plus GA parameter } \\
\text { optimization for fuzzy control }\end{array}$ & Fruit storage control \\
\hline 1997 & Noguchi and Terao & ANN simulation and GA optimization & $\begin{array}{l}\text { Path planning of an agricultural mobile robot bottom of } \\
\text { form }\end{array}$ \\
\hline $2001 b$ & Odhiambo et al. & Conceptual and structural fusion of FL and ANN & ET model optimization \\
\hline 2001 & Liu et al. & ANN modeling plus GA parameter optimization & Setting target corn yields \\
\hline 2001 & Jindal and Srisawas & PNN trained with GA & Classification of snack foods \\
\hline 2001 & Qu et al. & ALN decision tree & $\begin{array}{l}\text { Function approximation to convert the measurements of } \\
\text { an electronic nose into odor concentrations }\end{array}$ \\
\hline 2001 & Miu & FL and GA & $\begin{array}{l}\text { Optimization of design and functional parameters of } \\
\text { threshing units }\end{array}$ \\
\hline 2001 & Miu and Perhinschi & FL and GA & $\begin{array}{l}\text { Optimization of design and functional parameters of } \\
\text { threshing units }\end{array}$ \\
\hline 2003 & Morimoto et al. & ANN modeling plus GA parameter optimization & $\begin{array}{l}\text { Dynamic optimization for tomato cool storage to minimize } \\
\text { water loss }\end{array}$ \\
\hline 2003 & Jindal and Sritham & PNN trained with GA & Classification of eggs to detect eggshell cracks \\
\hline 2003 & Andriyas et al. & FCM clustering for RBF training & Prediction of the performance of vegetative filter strips \\
\hline 2003 & Chtioui et al. & SOM with FCM clustering & Color image segmentation of edible beans \\
\hline 2003 & Lee et al. & ANFIS modeling & Prediction of multiple soil properties \\
\hline 2003 & Neto et al. & ANFIS classification & Adaptive image segmentation for weed detection \\
\hline 2004 & Odhiambo et al. & $\begin{array}{l}\text { Fuzzy-neural network unsupervised } \\
\text { classification }\end{array}$ & Classification of soils \\
\hline 2004 & Meyer et al. & ANFIS classification & $\begin{array}{l}\text { Classification of uniform plant, soil, and residue color } \\
\text { images }\end{array}$ \\
\hline 2004 & Goel et al. & Fuzzy c-means clustering for RBF training & $\begin{array}{l}\text { Prediction of sediment and phosphorous movement } \\
\text { through vegetative filter strips }\end{array}$ \\
\hline 2004 & Jain and Srinivasulu & ANN trainined by GA & Rainfall-runoff modeling \\
\hline 2006 & Madeiro et al. & GA parameter search for ANN & Approximation of sugarcane maturation curves \\
\hline 2006 & Hashimoto et al. & ANN modeling plus GA parameter optimization & Greenhouse cropping control \\
\hline 2006 & Oliveira et al. & GA parameter search for ANN & $\begin{array}{l}\text { Forecasting of agronomical performance indicators in } \\
\text { sugarcane harvest }\end{array}$ \\
\hline 2006 & Ferentinos et al. & ANN parameterized by GA & Greenhouse cultivation control \\
\hline 2006 & Hancock and Zhang & ANFIS classification & Hydraulic vane pump health classification \\
\hline 2006 & Lakshmi et al. & ANN training plus GA parameter optimization & Automatic calibration of complex watershed models \\
\hline 2006 & Pearson and Wicklow & ANN trained by GA & $\begin{array}{l}\text { Classification of corn kernels for detection of fungi } \\
\text { infection }\end{array}$ \\
\hline 2007 & Xiang and Tian & $\begin{array}{l}\text { ANN modeling plus ANFIS training of FL } \\
\text { controller }\end{array}$ & Outdoor automatic camera parameter control \\
\hline
\end{tabular}

of input-output examples selected to cover the data hyperspace of the sites evaluated.

\subsection{Soil analysis}

In a study of soil profiles, Odhiambo et al. (2004) combined an ANN and a fuzzy system in series and applied the fuzzy-neural network classifier for unsupervised clustering and classification of soil profiles using ground-penetrating radar imagery. After the ANN classifies soil profile strips into a certain number of clusters determined dynamically, the fuzzy membership values for each profile strip are evaluated in the set of classified clusters. To predict sediment and phosphorous movement, Goel et al. (2004) used fuzzy c-mean clustering algorithms for the RBF ANN model through the data from vegetative filter strips.

To simultaneously predict water content and salinity using the frequency-response soil data, Lee et al. (2003) developed partial least-squares and ANFIS (Adaptive-Network Fuzzy Inference System) models at different water content and salinity levels measured with the four-electrode Wenner array method.

\subsection{Precision agriculture}

Xiang and Tian (2007) developed a complete artificially intelligent controller based on an ANN and an ANFIS for implementing the controller to automatically adjust multispectral camera parameters for compensation of changes in natural lighting and to acquire white-balanced images. Oliveira et al. (2006) proposed a two- step decision support system starts with an ANN followed by GAs for heuristic search to recommend suitable sugarcane areas to be harvested. Liu et al. (2001) designed a feedforward, completely connected, BP-trained ANN to approximate the nonlinear yield function relating corn yield to factors influencing yield. By stratified sampling based on rainfall, some of the data were excluded from the training set and used to verify the yield prediction accuracy of the ANN. After the ANN was developed and trained, optimization of the fifteen input factors was studied with a GA to determine maximum yield.

\section{Support vector machines}

SVMs as a new set of supervised generalized linear classifiers, have been introduced to solve problems and have attracted greater interest recently in agricultural and biological engineering. SVMs are closely related to neural networks. In fact, an SVM model using sigmoid kernel function is equivalent to a two-layer perceptron neural network. Using a kernel function, SVMs are alternative training methods for polynomial, radial basis function, and multilayer perceptron classifiers in which the weights of the network are found by solving a quadratic programming problem with linear constraints, rather than by solving a nonconvex, unconstrained minimization problem as in standard ANN training. SVMs have often higher classification accuracies than multilayer perceptron ANNs.

SVMs, as a set of supervised generalized linear classifiers, have often been found to provide higher classification accuracies than 


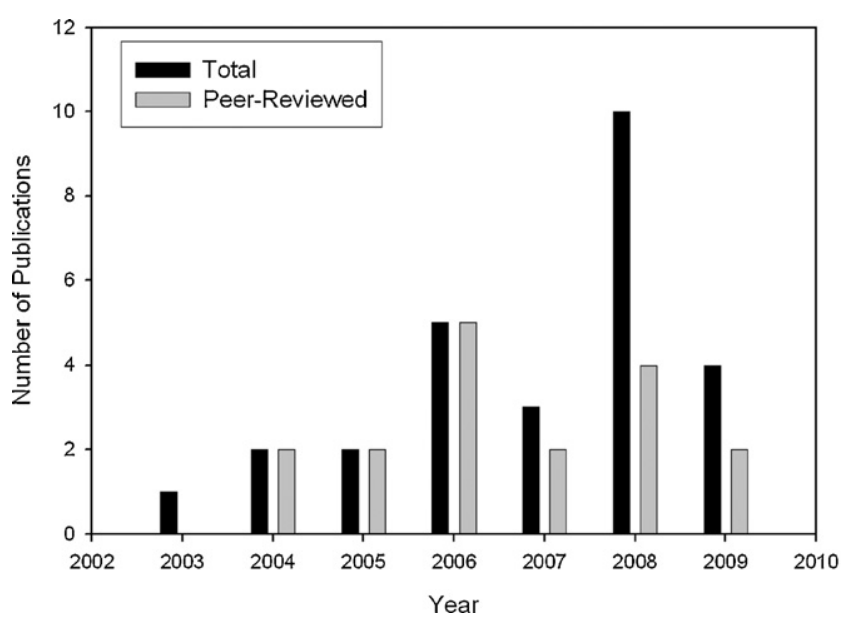

Fig. 4. Publications on applications of SVMs in agricultural and biological engineering.

other widely used pattern classification techniques such as MLP neural networks. In agricultural and biological engineering, the growing interest in SVMs is illustrated in Fig. 4. Fig. 4 indicates that although the number of peer reviewed publications on this topic did not increase steadily over the past few years, an increasing trend in all papers suggest increasing usage of established techniques which do not represent original research developments. The successful implementations of SVMs in agricultural and biological engineering are listed in Table 2.

The growing interest in SVMs are due to: (1) their intrinsic effectiveness with respect to traditional classifiers, which results in high classification accuracies and very good generalization capability; (2) the limited effort required for architecture design (i.e., they involve few control parameters); and (3) the possibility of solving the learning problem according to linearly constrained quadratic programming methods (Melgani and Bruzzone, 2004).

In soil analysis, Lamorski et al. (2008) estimated soil hydraulic parameters from measured soil properties using SVMs. The results of the research indicated that the three-parameter SVMs performed mostly better than or with the same accuracy as the elevenparameter ANNs. The advantage of SVM was more pronounced at soil matric potentials where larger relative errors have been encountered and the correlation between predicted and measured soil water contents was lower. And most recently, Twarakavi et al. (2009) developed SVMs for estimating the hydraulic parameters describing the soil water retention and hydraulic conductivity. In estimating water contents and saturated hydraulic conductivities the SVM-based method predicted the hydraulic parameters,

Table 2

Papers and reports on applications of SVMs in agricultural and biological engineering.

\begin{tabular}{|c|c|c|c|}
\hline Year & Author & Application method & Application area \\
\hline 2003 & Fletcher and Kong & SVM classification & $\begin{array}{l}\text { Classifying feature vectors and decide whether each pixel in hyperspectral } \\
\text { fluorescence images of poultry carcasses falls in normal or skin tumor } \\
\text { categories }\end{array}$ \\
\hline 2004 & Brudzewski et al. & SVM neural network classification & Classification of milk by an electronic nose \\
\hline 2004 & Tian et al. & SVM classification & Classification for recognition of plant disease \\
\hline 2005 & Pardo and Sberveglieri & SVM with RBF kernel of RBF & Classification of electronic nose data \\
\hline 2005 & Pierna et al. & SVM classification & $\begin{array}{l}\text { Classification of modified starches by Fourier transform infrared } \\
\text { spectroscopy }\end{array}$ \\
\hline 2006 & Chen et al. & SVM classification & Identification of tea varieties by computer vision \\
\hline 2006 & Karimi et al. & SVM classification & Classification for weed and nitrogen stress detection in corn \\
\hline 2006 & Onaran et al. & SVM classification & $\begin{array}{l}\text { Detection of underdeveloped hazenuts from fully developed nuts by } \\
\text { impact acoustics }\end{array}$ \\
\hline 2006 & Pierna et al. & SVM classification & $\begin{array}{l}\text { Discrimination of screening of compound feeds using NIR hyperspectral } \\
\text { data }\end{array}$ \\
\hline 2006 & Wang and Paliwal & Least-squares SVM classification & Discrimination of wheat classes with NIR spectroscopy \\
\hline 2007 & Jiang et al. & $\begin{array}{l}\text { Gaussian kernel based SVM } \\
\text { classification }\end{array}$ & $\begin{array}{l}\text { Black walnut shell and meat classification using hyperspectral } \\
\text { fluorescence imaging }\end{array}$ \\
\hline 2007 & Oommen et al. & SVM modeling and prediction & $\begin{array}{l}\text { Simulation of daily, weekly, and monthly runoff and sediment yield fron a } \\
\text { watershed }\end{array}$ \\
\hline 2007 & Zhang et al. & $\begin{array}{l}\text { Multi-class SVM with kernel of RBF } \\
\text { neural network }\end{array}$ & $\begin{array}{l}\text { Classification to differentiate individual fungal infected and healthy wheat } \\
\text { kernels. }\end{array}$ \\
\hline 2008 & Fu et al. & $\begin{array}{l}\text { Least-squares SVM modeling and } \\
\text { prediction }\end{array}$ & Quantification of vitamin C content in kiwifruit using NIR spectroscopy \\
\hline 2008 & Khot et al. & SVM classification & Classification of meat with small data set \\
\hline 2008 & Kovacs et al. & SVM modeling and prediction & $\begin{array}{l}\text { Prediction of different concentration classes of instant coffee with } \\
\text { electronic tongue measurements }\end{array}$ \\
\hline 2008 & Lamorski et al. & SVM modeling and prediction & Estimation of hydraulic parameters from measured soil properties \\
\hline 2008 & Li et al. & Least-squares SVM classification & Classification of paddy seeds by harvest year \\
\hline 2008 & Peng and Wang & $\begin{array}{l}\text { Least-squares SVM modeling and } \\
\text { prediction }\end{array}$ & $\begin{array}{l}\text { Prediction of pork meat total viable bacteria count with hyperspectral } \\
\text { imaging }\end{array}$ \\
\hline 2008 & Sun et al. & SVM modeling and prediction & On-line assessing internal quality of pears using visible/NIR transmission \\
\hline 2008 & Trebar and Steele & SVM classification & Classification of forest data cover types \\
\hline 2008 & Wu et al. & Least-squares SVM classification & $\begin{array}{l}\text { Identification of varieties of Chinese cabbage seeds using visible and NIR } \\
\text { reflectance spectroscopy }\end{array}$ \\
\hline 2008 & Yu et al. & $\begin{array}{l}\text { Least-squares SVM modeling and } \\
\text { prediction }\end{array}$ & Rice wine composition prediction by visible/NIR spectroscopy \\
\hline 2009 & Deng et al. & SVM classification & Classification of intact and cracked eggs \\
\hline 2009 & Fu et al. & $\begin{array}{l}\text { Least-squares SVM modeling and } \\
\text { prediction }\end{array}$ & Quantification of pear firmness using NIR spectroscopy \\
\hline 2009 & Qi and Ma & SVM classification & $\begin{array}{l}\text { Class recognition of rice blast with multispectral imaging to supervise } \\
\text { variable spray }\end{array}$ \\
\hline 2009 & Shao et al. & $\begin{array}{l}\text { Least-squares SVM modeling and } \\
\text { prediction }\end{array}$ & $\begin{array}{l}\text { Quantitative assessment of amylose and protein content in rice after } \\
\text { gamma irradiation using infrared spectroscopy and chemometrics }\end{array}$ \\
\hline 2009 & Twarakavi et al. & SVM modeling and prediction & $\begin{array}{l}\text { Estimation of hydraulic parameters describing the soil water retention and } \\
\text { hydraulic conductivity }\end{array}$ \\
\hline
\end{tabular}


which mostly improved compared with those obtained using the ANN-based method.

In the studies of crops for precision agriculture, Karimi et al. (2006) evaluated SVM as a tool for classifying airborne hyperspectral images taken over a corn field. The classification was performed with respect to nitrogen application rates and weed management practices, and the classification accuracy was compared with those obtained by an ANN model on the same data. The SVM method resulted in very low misclassification rates as compared to the ANN approach for all cases. Detection of stresses in early crop growth stage using the SVM method could aid in effective early application of site-specific remedies to timely in-season interventions. Tian et al. (2004) used the SVM and chromaticity moment for recognition of plant diseases based on the features of color texture image of plant disease. The experimental results proved that the SVM method had excellent classification and generalization ability in solving learning problem with small training set of sample, and could fit for classification of plant disease.

Trebar and Steele (2008) employed a SVM for classification of forest data cover types. In this study, a large, imbalanced data set in different forest cover type classes was transformed into a number of new data sets and a SVM was used to conduct a binary classification of balanced and imbalanced data sets with various sizes. The use of distributed SVM architectures basically reduced the complexity of the quadratic optimization problem of very large data sets. The experimental results of distributed SVM architectures showed the improvement of the accuracy for larger data sets in comparison to a single SVM classifier and their ability to improve the correct classification of the minority class.

\section{Comparison and limitations of soft computing techniques}

There are limits on soft computing we need to be aware of in theoretical study and practical application. Tikk et al. (2003) studied the approximation behavior of soft computing techniques. In the study, the authors conducted a survey of the results of universal approximation theorems achieved thus far in various soft computing areas. These techniques center mainly in fuzzy control and neural networks. The authors point out that these techniques have common approximation behavior in the sense that an arbitrary function from a certain set of functions (usually the set of continuous function) can be approximated with arbitrary accuracy on a compact domain. This means that fuzzy systems and neural networks have the ability to approximate any function to an arbitrary degree of accuracy. However, for the approximation, unbounded numbers of "building blocks" (i.e. fuzzy sets or hidden neurons) are needed to achieve the prescribed accuracy. If the number of building blocks is restricted, it is proved for some fuzzy and neural systems that the universal approximation property is lost. Therefore, it is reasonable to make a trade-off between accuracy and the number of the building blocks in determining functional relationships. A typical practical application of this recommendation is to determine the number of hidden neurons incrementally in ANN training for acceptable function approximation and better generalization.

Compared to classical logic, FL is not always accurate because the results are often perceived as an estimate. Also, fuzzy systems typically require the difficult and time-consuming process of knowledge acquisition although they provide the understandable form of knowledge representation.

ANNs are powerful computing techniques, which are designed to mimic human learning processes by establishing linkages between process input and output data. These techniques have been widely applied with advanced development with their unique advantages, such as no underlying assumption about the distribution of data, arbitrary decision boundary capabilities, universal approximation capabilities, easy adaptation to different types and structures of data, ability to fuzzy output values to enhance classification, and good generalization capabilities. However, ANNs have some disadvantages in common, which need to be considered in practical application:

\section{- Black box}

ANNs are black box in nature. Therefore, if the problem is to find the output response to the input in system identification, ANNs can be a good fit. However, if the problem is to specifically identify causal-effective relationship between input and output, ANNs have only limited ability to do it compared with conventional statistical methods.

- Long computing time

ANN training needs to iteratively determine network structure and update connection weights. Also, data used for training may contain certain degree of noises. Therefore, ANN training is a time-consuming process. With a typical personal computer or work station, the BP algorithm will take a lot of memory and may take minutes, hours, days and even longer before the network converges to the optimal point with minimum mean square error. Conventional statistical regression with the same set of data, on the contrary, may generate results in seconds using the same computer.

- Local minima

Due to addition of hidden nodes and layer(s) and the nonlinearity of the activation function of each hidden nodes and/or output nodes in network structure, ANN training has the possibility to produce for complex error surfaces which contain many minima such as use of BP algorithm for training MLPs. Since some minima are deeper than others, it is possible that the algorithm will not find a global minimum. Instead, the network may fall into local minima, which represent suboptimal solutions instead of optimal.

- Overfitting

With too much training time, too many hidden nodes, or too large training data set, the network will overfit the data and have a poor generalization, i.e. high accuracy for training data set but poor interpolation of testing data. This is an important issue being investigated in ANN research and applications (Huang, 2009).

Although ANNs have strong capabilities of learning and adaptation with a "black box" nature that deals with inputs and outputs, they represent knowledge implicitly and may produce results that are difficult to interpret. ANNs also may require long training times on noisy data. Therefore, ANNs may not be needed when traditional methods are appropriate.

GAs work on their own internal rules and are good for complex or loosely defined problems using their inductive nature without the need to know any rules of the problem. However, with use of this inductive ability alone, the algorithms do not necessarily evolve to the optimal solution. GAs always have a risk finding a suboptimal solution. BI uses prior probabilities. However, prior probabilities are intrinsically subjective, which can be different from person by person. This may be the fundamental limit of BI.

Usually, learning by DTs is fast, and the result is easily interpreted by human specialists. However, the learning could produce overfitting, the output attribute of DTs need to be categorical, and each decision is limited to one output attribute. The induction process usually selects only a small number of the available attributes so that information that is distributed on a large number of attributes (with each attribute carrying only limited information about the class) cannot be handled adequately, resulting in suboptimal prediction accuracy. In such situations, Bayesian classifiers and 
ANNs are often used instead.SVMs have gained popularity in many traditionally ANN dominated fields. Use of the SVM always found the minimum globally, which eliminates the local minimum issue happened in ANN training. However, SVMs were originally developed to solve binary classification problems. How to effectively extend it for multi-class classification is still an ongoing research issue. Typically, a multiple class classifier can be constructed by combining several binary classifiers. Further, all classes can be considered at once. Hsu and Lin (2002) gave decomposition implementations for two such "all-together" methods. They compared the performance with three methods based on binary classifications: one-against-all, one-against-one, and Directed Acyclic Graph SVM (DAGSVM). The experiments indicated that the one-againstone and DAG methods are more suitable for practical use than the other methods.

\section{The future}

As described above, each soft computing technique has its own limitations. The fusion of two or three of these techniques will continue to be one of the major trends in soft computing engineering applications. Fuzzy and neuro-fuzzy systems represent knowledge in an explicit form, such as fuzzy rules, rather than in an implicit form as ANNs alone. Accordingly, FL and ANNs are merged to inherit the advantages of both paradigms and to avoid their drawbacks.

Recently, with the development of electronics and information technologies, 3S (remote sensing (RS), global positioning system (GPS), and geographic information system (GIS)) technologies and variable rate technology (VRT) have started to become available to agricultural production for crop seeding, irrigation, and chemical application. For effective applications of the technologies, a system integration is needed. For the system integration, FL is a critical tool to establish 'If-Then' rules to represent extensive human knowledge to build up a knowledge-based system to connect independent components together. In the system a knowledge base obtains the information from various sources such as scientists, engineers, and farmers and provides advice suited to a geographic location based on local weather, soil and water data from GPS, GIS and traditional knowledge archives. The weather data are collected from the different sensors on a daily basis for solar radiation, air temperature, rainfall, and wind run. The inference engine analyzes user query and sends information requests to the knowledge base and matches them with the stored knowledge rules through fuzzy 'If-Then' rules or algorithms specific to the particular domain or discipline. Then the control system outputs the decision of the inference engine to the variable rate equipment for crop seeding and chemical application. A comprehensive model base includes crop growth model, health model, perhaps other models that describes the condition of the crop so that information will be provided for decision support to result in more precise timing of seeding, more accurate use of seed, fertilizers and, irrigated water in order to enhance crop production and environmental protection as well. A method base contains linear and nonlinear methods of pattern recognition, statistics, and soft computing such as FL, ANNs and GAs. In the modeling process, one or more methods can be activated to assemble and generate designated model structure and parameters.

ANNs have been used as a powerful tool in solving problems in scientific research and engineering applications. ANNs have their own limitations to restrict them as a substitute of traditional methods such as statistical regression, pattern recognition, and time series analysis. In the next decade or so with advanced development of computer power, ANNs will continue to develop new applications in various fields in agricultural and biological engineering. As a powerful alternative to conventional methods, ANNs will be studied more to develop approaches to overcoming problems of ANNs in general or in a specific research area. In food science and engineering, soil and water relationships for crop management, and decision support for precision agriculture, more applications of ANNs may be expected. ANNs will be continuously applied standalone or fusion with other soft computing techniques. Areas of study may actively involve food quality and safety, soil and water resources management, crop pest management, and precision agriculture.

For effective research and development it may be possible to generate guidelines for predetermining optimal ANN structures and training algorithms. For process statistical modeling, additional research topics may be to establish generic procedures to include significant variables to and exclude non-significant ones from ANN models and to add confidence limits on the output predictions and parameter estimations. These developments will permit ANNs to also utilize the techniques of conventional statistics.

SVMs appeared as a new technique which has advanced soft computing development. In practical applications, SVMs often produced high classification accuracies and very good generalization capabilities compared with ANNs. Also, in the process of modeling SVMs require less effort in setting up control parameters for architecture design. SVM models are close to classical MLP neural networks. Using a kernel function, SVMs are an alternative training method for polynomial, RBF and MLP classifiers in which the weights of the network are found by solving a quadratic programming problem with linear constraints, rather than by solving a non-convex, unconstrained minimization problem as in standard neural network training. With the advantages of SVMs over ANNs and the growing interests of SVMs, it can be expected that in the next decade SVMs will be more actively used in agricultural and biological engineering.

No matter which soft computing method is used, adaptive learning can be a powerful tool when also implemented to appropriately exploit the potential synergy between methods, some that can include input from sensors. An example of how this can work involves model-based irrigation scheduling with assistance from soil water sensors. Thomson (1998) explained a method by which granular matrix soil water sensors were used to provide "feedback" or correction to two input parameters of the water balance component of the Pnutgro 1.02 growth model (Boote et al., 1989). Soil water sensors inferred relative water uptake in the root zone and corrected the root growth function influencing the depth of water regulation. The goal was to improve model predictions so that the model could run stand-alone after sensors provided correction data during several soil drying cycles. Experiments indicated temporal convergence of model-based representations of soil water potential on sensor-based representations as two parameters (soil-water parameter Drained Upper Limit or DUL) and root weighting factors were adjusted.

In the soil and water context for crop management and decision support for precision agriculture more applications of soft computing techniques, especially SVMs standalone or fused with other soft computing techniques and sensor-derived information, may be expected. Areas of application might involve classification for agricultural soil spatial distribution, water resource optimization for irrigation planning, detection and classification of crop stress and pests (weeds, insects and diseases) detection, analysis of remote sensing imagery, study of crop and yield, and field prescriptions for variable rate chemical application.

Another trend in soft computing applications is likely to be the fusion of soft computing and hard computing. Although no successful applications of hard and soft computing fusion in agricultural and biological engineering could be found thus far, the technique shows great potential for future research over the next decade. The fusion of soft computing and hard computing should be able to provide innovative solutions to the problems with high-performance, cost-effective, and reliable computing systems. Many publications 
are useful to help develop such computing systems. Ovaska (2005) edited a book that combines the experience of many internationally recognized experts in the soft- and hard-computing research worlds to present practicing engineers with the broadest possible array of methodologies for developing innovative and competitive solutions to real-world problems. Each of the chapters illustrates the wide-ranging applicability of the fusion concept in such critical areas as

- computer security and data mining;

- electrical power systems and large-scale plants;

- motor drives and tool wear monitoring;

- user interfaces and the World Wide Web; and

- aerospace and robust control.

Ovaska et al. (2006) clarified the present vagueness related to the fusion of soft computing and hard computing. Different fusion schemes were classified as 12 core categories and six supplementary categories, and the characteristic features of soft computing and hard computing constituents in practical fusion implementations were discussed as well. Sick and Ovaska (2007) introduced a multi-dimensional categorization scheme for fusion techniques and applied it by analyzing several fusion techniques where the soft computing part was realized by a neural network. The categorization scheme facilitated the discussion of advantages or drawbacks of certain fusion approaches, thus supporting the development of novel fusion techniques and applications.

\section{References}

Abraham, A., Jain, R., Thomas, J., Han, S.Y., 2007. D-SCIDS: distributed soft computing intrusion detection system. Journal of Network and Computer Applications 30, 81-98.

Anagu, I., Ingwersen, J., Utermann, J., Streck, T., 2009. Estimation of heavy metal sorption in German soils using artificial neural networks. Geoderma 152 (1-2), 104-112.

Al-Faraj, A., Meyer, G.E., Horst, G.L., 2001. A crop water stress index for tall fescue (Festuca arundinacea Schreb.) irrigation decision-making-a fuzzy logic method. Computers and Electronics in Agriculture 32, 69-84.

Altendorf, C.T., Elliott, R.L., Stevens, E.W., Stone, M.L., 1999. Development and validation of a neural network model for soil water content prediction with comparison to regression techniques. Transactions of the ASAE 42 (3), 691-699.

Ambuel, J.R., Colvin, T.S., Karlen, D.L., 1994. A fuzzy logic yield simulator for prescription farming. Transactions of the ASAE 37 (6), 1999-2009.

Anderson, J.A., Silverstein, J.W., Ritz, S.A., Jones, R.S., 1977. Distinctive features, categorical perception, and probability learning: some applications of a neural model. Psychological Review 84, 413-451.

Andriyas, S., Negi, S.C., Rudra, R.P., Yang, S.X., 2003. Modelling total suspended solids in vegetative filter strips using artificial neural networks. American Society of Agricultural Engineers, St. Joseph, MI, ASAE paper number: 032079.

Bajwa, S.G., Tian, L.F., 2001. Aerial CIR remote sensing for weed density mapping in a soybean field. Transactions of the ASAE 44 (6), 1965-1974.

Bajwa, S.G., Bajcsy, P., Groves, P., Tian, L.F., 2004. Hyperspectral image data mining for band selection in agricultural applications. Transactions of the ASAE 47 (3), 895-907.

Bayes, T., 1763. An essay towards solving a problem in the doctrine of chances. Philosophical Transactions of the Royal Society 53, 370-418.

Bonissone, P.P., 1994. Fuzzy logic controllers: an industrial reality. In: Zurada, J.M., Marks II, R.J., Robinson, C.J. (Eds.), Computational Intelligence: Imitating Life. IEEE Press, Piscataway, NJ, pp. 316-327.

Boote, K.J., Jones, J.W., Hoogenboom, G., Wilkerson, G.G., Jagtap, S.S., 1989. PNUTGRO v. 1.02. Peanut Crop Growth Simulation Model. User's Guide. Florida Agricultural Experiment Station Journal No. 8420. University of Florida, Gainesville, FL, 76 pp.

Bragato, G., 2004. Fuzzy continuous classification and spatial interpolation in conventional soil survey for soil mapping of the lower Piave plain. Geoderma 118 (1-2), 1-16.

Brudzewski, K., Osowski, S., Markiewicz, T., 2004. Classification of milk by means of an electronic nose and SVM neural network. Sensors and Actuators B 98 (2-3), 291-298.

Bruton, J.M., McClendon, R.W., Hoogenboom, G., 2000. Estimation daily pan evaporation with artificial neural networks. Transactions of the ASAE 43 (2), 491-496.

Burges, C.J.C., 1998. A tutorial on support vector machines for pattern recognition. Data Mining and Knowledge Discovery 2, 121-167.

Burks, T.F., Shearer, S.A., Gates, R.S., Donohue, K.D., 2000. Backpropagation neural network design and evaluation for classifying weed species using color image texture. Transactions of the ASAE 43 (4), 1029-1037.
Cai, X., McKinney, D.C., Lasdon, L., 2001. Solving nonlinear water management models using a combined genetic algorithm and linear programming approach. Advances in Water Resources 24 (6), 667-676.

Carpenter, G.A., Grossberg, S., 1987. ART 2: self-organization of stable category recognition codes for analog input patterns. Applied Optics 26, 4919-4930.

Carpenter, G.A., Grossberg, S., Rosen, D.B., 1991. Fuzzy ART: fast stable learning and categorization of analog patterns by an adaptive resonance system. Neural Networks 4, 759-771.

Charniak, E., 1991. Bayesian networks without tears. AI Magazine 12 (4), 50-63.

Chen, Q., Zhao, J., Cai, J., Wang, X., 2006. Study on identification of tea using computer vision based on support vector machine. Chinese Journal of Scientific Instruments 27 (12), 1704-1706.

Chen, Y., Zheng, J., Xiang, H., Huang, S., 2006. Study on an intelligent system for precision pesticide application based on fuzzy control and machine vision. American Society of Agricultural and Biological Engineers, St. Joseph, MI, ASABE paper number: 061129.

Chen, C.T., Chen, S., Hsieh, K.W., Yang, H.C., Hsiao, S., Yang, I.C., 2007. Estimation of leaf nitrogen content using artificial neural network with cross-learning scheme and significant wavelengths. Transactions of the ASABE 50 (1), 295301

Chinchuluun, R., Lee, W.S., Ehsani, R., 2007. Citrus yield mapping system on a canopy shake and catch harvester. American Society of Agricultural and Biological Engineers, St. Joseph, MI, ASABE paper number: 073050.

Cho, S.I., Ki, N.H., 1999. Autonomous speed sprayer guidance using machine vision and fuzzy logic. Transactions of the ASAE 42 (4), 1137-1143.

Cho, S.I., Lee, D.S., Jeong, J.Y., 2002. Weed-Plant discrimination by machine vision and artificial neural network. Biosystems Engineering 83 (3), 275-328.

Chtioui, Y., Panigrahi, S., Backer, L.F., 2003. Self-organizing map combined with a fuzzy clustering for color image segmentation of edible beans. Transactions of the ASAE 46 (3), 831-838.

Cleland, J., Turner, W., Wang, P., Espy, T., Chappell, P.J., Spiegel, R.J., Bose, B., 1992. Fuzzy logic control of AC induction motors. Fuzzy Systems 8 (12), 843 850.

Clemmens, A.J., Keats, J.B., 1992. Bayesian inference for feedback-control. II. Surface irrigation example. Journal of Irrigation \& Drainage Division ASCE 118 (3), 416-432.

Cockx, L., Van Meirvenne, M., Vitharana, U.W.A., Verbeke, L.P.C., Simpson, D., Saey, T., Van Coillie, F.M.B., 2009. Extracting topsoil information from EM38DD sensor data using a neural network approach. Soil Science Society of America Journal 73, 2051-2058

Cohen, Y., Cohen, A., Timar, D., Gazit, Y., 2006. Developing spatial decision support system for medfly control in Israel. American Society of Agricultural and Biological Engineers, St. Joseph, MI, ASABE paper number: 061152.

Cristianini, N., Taylor, J.S., 2000. An Introduction to Support Vector Machines and Other Kernel-Based Learning Methods. Cambridge University Press, New York.

Cybenko, G.V., 1989. Approximation by superpositions of a sigmoidal function, Mathematics of Control. Signals and Systems 2 (4), 303-314.

Darwin, C., 1859. On the Origin of Species. John Murray, London, UK.

Deng, X., Wang, Q., Wu, L., Gao, H., Wen, H., Wang, S., 2009. Eggshell crack detection by acoustic impulse response and support vector machine. African Journal of Agricultural Research 4 (1), 40-48.

Diaz, B., Ribeiro, A., Bueno, R., Guinea, D., Barroso, J., Ruiz, D., Fernadez-Quintanilla, C., 2005. Modelling wild-oat density in terms of soil factors: a machine learning approach. Precision Agriculture 6 (2), 213-228.

Drummond, S.T., Sudduth, K.A., Joshi, A., Birrell, S.J., Kitchen, N.R., 2003. Statistical and neural methods for site-specific yield prediction. Transactions of the ASAE 46 (1), 5-14.

Duda, R.O., Hart, P.E., Stork, D.G., 2001. Pattern Classification, 2nd ed. Wiley, New York.

Eddy, D.M., 1982. Probabilistic reasoning in clinical medicine: problems and opportunities. In: Kahneman, D., Slovic, P., Tversky, A. (Eds.), Judgement under Uncertainty: Heuristics and Biases. Cambridge University Press, Cambridge, UK.

Edwards, W., 1982. Conservatism in human information processing. In: Kahneman, D., Slovic, P., Tversky, A. (Eds.), Judgement under Uncertainty: Heuristics and Biases. Cambridge University Press, Cambridge, UK.

Eerikäinen, T., Linko, P., Linko, S., Siimes, T., Zhu, Y.H., 1993. Fuzzy logic and neural networks applications in food science and technology. Trends in Food Science \& Technology 4, 237-242.

EET (Electronics Engineering Times), 1991. Europe gets into fuzzy logic. Electronics Engineering Times, November 11, 1991.

El-Faki, M.S., Zhang, N., Peterson, D.E., 2000. Weed detection using color machine vision. Transactions of the ASAE 43 (6), 1969-1978.

Elgaali, E., Garcia, L.A., Ojima, D.S., 2006. Sensitivity of irrigation water balance to climate change in the great plains of Colorado. Transactions of the ASABE 49 (5), 1315-1322.

Fang, H.L., Liang, S.L., Kuusk, A., 2003. Retrieving leaf area index using a genetic algorithm with a canopy radiative transfer model. Remote Sensing of Environment 85 (3), 257-270

Ferentinos, K.P., Albright, L.D., 2002. Prediction neural network modeling of pH and electrical conductivity in deep-trough hydroponics. Transactions of the ASAE 45 (6), 2007-2015

Ferentinos, K.P., Arvanitis, K.G., Tantau, H.J., Sigrimis, N., 2006. Special aspects of IT for greenhouse cultivation. 294-312 of Chapter 5 Precision Agriculture, in CIGR Handbook of Agricultural Engineering Volume VI Information Technology. Edited by CIGR-The International Commission of Agricultural Engineering; Volume Editor, Axel Munack. ASABE. St. Joseph, MI. 
Ferguson, R.B., Lark, R.M., Slater, G.P., 2003. Approaches to management zone definition for use of nitrification inhibitors. Soil Science Society of America Journal 67, 937-947.

Fidêncio, P.H., Ruisánchez, I., Poppi, R.J., 2001. Application of artificial neural networks to the classification of soils from São Paulo state using near-infrared spectroscopy. Analyst 126, 2194-2200.

Flamig, B, 2000. Discover the value of data mining: turning piles of stagnant information into golden opportunities. Reference Series: How Computers Work, Part II 4(3), 120-125. Smart Computing, Lincoln, NE.

Fletcher, J.T., Kong, S.G., 2003. Principal component analysis for poultry tumor inspection using hyperspectral fluorescence imaging. In: Proceedings of the International Joint Conference on Neural Networks, vol. 1, Portland, Oregon, pp. 149-153.

Fogel, L.J., Owens, A.J., Walsh, M.J., 1966. Artificial Intelligence through Simulated Evolution. John Wiley, New York

Freeland, R.S., Odhiambo, L.O., 2007. Subsurface characterization using textural features extracted from GPR data. Transactions of the ASABE 50 (1), 287-293.

Fu, X., Ying, Y., Xu, H., Yu, H., 2008. Support vector machines and near infrared spectroscopy for quantification of vitamin C content in kiwifruit. American Society of Agricultural and Biological Engineers, St. Joseph, MI, ASABE paper number: 085204.

Fu, X., Ying, Y., Xu, H., 2009. Quantitative analysis of fruit firmness by near infrared spectroscopy and least-squares support vector machine. American Society of Agricultural and Biological Engineers, St. Joseph, MI, ASAE paper number: 096475.

Ghahramani, Z., 1997. Learning dynamic Bayesian networks. Lecture Notes in Computer Science 1387, 168-197.

Gigerenzer, G., Hoffrage, U., 1995. How to improve Bayesian reasoning without instruction: frequency formats. Psychological Review 102, 684-704

Gil, Y., Sinfort, C., Guillaume, S., Brunet, Y., Palagos, B., 2008. Influence of micrometeorological factors on pesticide loss to the air during vine spraying: data analysis with statistical and fuzzy inference models. Biosystems Engineering 100, 184-197.

Goel, P.K., Prasher, S.O., Patel, R.M., Landry, J.A., 2001. Weed and nitrogen stress detection in corn using hyperspectral remote sensing. American Society of Agricultural Engineers, St. Joseph, MI, ASAE paper number: 01-1199.

Goel, P.K., Prasher, S.O., Patel, R.M., Landry, J.A., Bonnell, R.B., Viau, A.A., 2003. Classification of hyperspectral data by decision trees and artificial neural networks to identify weed stress and nitrogen status of corn. Computers and Electronics in Agriculture 39 (2), 67-93.

Goel, P.K., Andriyas, S., Rudra, R.P., Negi, S.C., 2004. Modeling sediment and phosphorous movement through vegetative filter strips using artificial neural networks and GRAPH. American Society of Agricultural Engineers, St. Joseph, MI, ASAE paper number: 042263.

Goldberg, D.E., Holland, J.H., 1988. Genetic algorithms and machine learning. Machine Learning 3 (2-3), 95-99.

Goldberg, D.E., 1989. Genetic Algorithms in Search, Optimization, and Machine Learning. Addison-Wesley, Reading, MA.

Grefenstette, J.J., 1994. Genetic algorithms for machine learning. http://citeseerx.ist.psu.edu/viewdoc/summary?doi=10.1.1.17.1053.

Grossberg, S., 1976. Adaptive pattern classification and universal recoding. 1. Parallel development and coding of neural feature detectors. Biological Cybernetics 23 , 187-202.

Grunwald, P., 1997. The minimum description length principle and non-deductive inference. In: Proceedings of the IJCAI Workshop on Abduction and Induction in AI, Nagoya, Japan.

Hancock, K.M., Zhang, Q., 2006. A hybrid approach to hydraulic vane pump condition monitoring and fault detection. Transactions of the ASABE 49 (4), 1203-1211.

Hashimoto, Y., Morimoto, T., De Baerdemaeker, J., 2006. Speaking plant/speaking fruit approaches. 244-259 of Chapter 5 Precision Agriculture, in CIGR Handbook of Agricultural Engineering Volume VI Information Technology. Edited by CIGR-The International Commission of Agricultural Engineering; Volume Editor, Axel Munack. ASABE. St. Joseph, MI

Hebb, D.O., 1949. The Organization of Behavior. Wiley, Hoboken, NJ

Hellendoorn, H., 1993. Design and development of fuzzy systems at siemens R\&D. In: Proceedings of Second IEEE International Conference on Fuzzy Systems, San Fransisco, CA, USA, pp. 1365-1370.

Hillier, F.S., Lieberman, G.J., 2005. Introduction to Operations Research. McGraw-Hill, Boston, MA

Hirota, K., 1993. Industrial Applications of Fuzzy Technology. Springer, Tokyo, Japan.

Hoffmann, F., Gao, X.Z., Olhofer, M., Satyadas, A., 2005. Editorial: application reviews. Applied Soft Computing 5, 261-264.

Holland, J.H., 1975. Adaptation in Natural and Artificial Systems. University of Michigan Press, Ann Arbor, MI

Holmblad, L.P., Ostergaard, J.J., 1982. Control of a cement kiln by fuzzy logic. In: Gupta, M.M., Sanchez, E. (Eds.), Fuzzy Information and Decision Processes. North-Holland, pp. 389-399.

Hopfield, J.J., 1982. Neural networks and physical systems with emergent computational abilities. Proceedings of the National Academy of Sciences 79 (8), 2554-2558.

Horikawa, S., Furuhashi, T., Uchikawa, Y., 1992. On fuzzy modelling using fuzzy neural networks with back propagation algorithm. IEEE Transactions on Neural Networks 3 (5), 801-806.

Hornik, K., Stinchcombe, M., White, H., 1989. Multilayer feedforward networks are universal approximators. Neural Networks 2 (5), 359-366.
Houck, C., Joines, J., Kay, M., 1998. A genetic algorithm for function optimization: a Matlab implementation. The GAOT Toolbox for Matlab: http://www.ie.ncsu.edu/mirage/GAToolBox/gaot/gaotindex.html.

Hsieh, K.W., Chen, S., Chang, W.H., Lee, M.T., Chen, C.T., 2001. A dynamic simulation model for seedling growth. Transactions of the ASAE 44 (6), 1949-1954.

Hsieh, K.W., Chen, S., Lai, J.H., Yang, I.C., 2003. Neural network analysis of environmental conditions influencing cabbage seedling quality. Transactions of the ASAE 46 (2), 501-506

Hsu, C.W., Lin, C.J., 2002. A comparison of methods for multi-class support vector machines. IEEE Transactions on Neural Networks 13, 415-425.

Huang, Y., 2009. Advances in artificial neural networks-methodological development and application. Algorithms 2, 973-1007.

Ingleby, H.R., Crowe, T.G., 2001. Neural network models for predicting organic mat ter content in Saskatchewan soils. Canadian Biosystems Engineering 43 (7) $1-5$.

Irmak, A., Jones, J.W., Batchelor, W.D., Irmak, S., Boote, K.J., Paz, J.O., 2006. Artificia neural network model as a data analysis tool in precision farming. Transactions of the ASABE 49 (6), 2027-2037.

Jain, A., Srinivasulu, S., 2004. Development of effective and efficient rainfall-runof models using integration of deterministic, real-coded genetic algorithms and artificial neural network techniques. Water Resource Research 40, w04302.

Jang, R.J.S., 1993. ANFIS: adaptive-network-based fuzzy inference system. IEEE Transactions on Systems, Man and Cybernetics 23 (3), 665-685.

Jang, R.J.S., Sun, C.T., 1995. Neuro-fuzzy modelling and control. Proceedings of the IEEE 83 (3), 378-406.

Jaynes, E.T., 1996. Probability theory with applications in science and engineering. http://bayes.wustl.edu/etj/science.pdf.html.

Jiang, L., Zhu, B., Jing, H., Chen, X., Rao, X., Tao, Y., 2007. Gaussian mixture model-based walnut shell and meat classification in hyperspectral fluorescence imagery. Transactions of the ASABE 50 (1), 153-160.

Jindal, V.K., Srisawas, W., 2001. Acoustic testing of snack food texture. American Society of Agricultural Engineers, St. Joseph, MI, ASAE paper number: 016038.

Jindal, V.K., Sritham, E., 2003. Detecting eggshell cracks by acoustic impulse response and artificial neural networks. American Society of Agricultural Engineers, St Joseph, MI, ASAE paper number: 036170.

Jones, D., Barnes, E.M., 2000. Fuzzy composite programming to combine remote sensing and crop models for decision support in precision crop management Agricultural Systems 65, 137-158.

Karimi, K., Prasher, S.O., McNairn, H., Bonnell, R.B., Dutilleul, P., Goel, P.K., 2005 Classification accuracy of discriminant analysis, artificial neural networks, and decision trees for weed and nitrogen stress detection in corn. Transactions of the ASAE 48 (3), 1261-1268.

Karimi, Y., Prasher, S.O., Patel, R.M., Kim, S.H., 2006. Application of support vector machine technology for weed and nitrogen stress detection in corn. Computers and Electronics in Agriculture 51 (1-2), 99-109.

Khalilmoghadam, B., Afyuni, M., Abbaspour, K.C., Jalalian, A., Dehghani, A.A., Schulin, R., 2009. Estimation of surface shear strength in Zagros region of Iran-a comparison of artificial neural networks and multiple-linear regression models. Geoderma 153 (1-2), 29-36.

Khoshnevis, B., Chignell, M.H., 1985. A framework for artificial intelligence applications software development. Computers in Industry 6 (5) 363-369.

Khot, L.R., Panigrahi, S., Woznica, S, 2008. Neural-network-based classification of meat: evaluation of techniques to overcome small dataset problems. Biological Engineering 1 (2), 127-143.

Kim, S., Cho, I., 1997. Neural network modeling and fuzzy control simulation for bread-baking process. Transactions of the ASAE 40 (3), 671-676.

Koller, M., Upadhyaya, S.K., 2005a. Relationship between soil-adjusted vegetation index and leaf area index for processing tomatoes. Applied Engineering in Agriculture 21 (5), 927-933.

Koller, M., Upadhyaya, S.K., 2005b. Prediction of processing tomato yield using a crop growth model and remotely sensed aerial images. Transactions of the ASAE 48 (6), 2335-2341.

Koller, M., Upadhyaya, S.K., 2005c. Relationship between modified normalized difference vegetation index and leaf area index for processing tomatoes. Applied Engineering in Agriculture 21 (5), 927-933.

Kovacs, Z., Kantor, D.B., Fekete, A., 2008. Comparison of quantitative determination techniques with electronic tongue measurements. American Society of Agricultural and Biological Engineers, St. Joseph, MI, ASABE paper number: 084879.

Krishnaswamy, M., Krishnan, P., 2002. Nozzle wear rate prediction using regression and neural network. Biosystems Engineering 82 (1), 49-56.

Kumar, N.K., Raju, S., Ashok, B., 2006. Optimal reservoir operation for irrigation of multiple crops using genetic algorithms. Journal of Irrigation and Drainage Engineering 132 (2), 123-129.

Kuo, S., Merkey, G.P., Liu, C., 2000. Decision support for irrigation project planning using a genetic algorithm. Agricultural Water Management 45 (3) 243-266.

Lakshmi, G., Sudheer, K.P., Chaubey, I., 2006. Auto calibration of complex watershed models using simulation-optimization framework. American Society of Agricultural and Biological Engineers, St. Joseph, MI, ASABE paper number: 062126.

Lamorski, K., Pachepsky, Y., Slawinski, C., Walczak, R.T., 2008. Using support vector machines to develop pedotransfer functions for water retention of soils in Poland. Soil Science Society of America Journal 72, 1243-1247.

Lark, R.M., 2000. Designing sampling grids from imprecise information on soil variability, an approach based on the fuzzy kriging variance. Geoderma 98 (1-2) 35-59. 
Lauritzen, S.L., 2003. Some modern applications of graphical models. In: Green, P.J., Richardson, S., Hjort, N.L. (Eds.), Highly Structured Stochastic Systems. Oxford University Press, Oxford, UK, pp. 13-28.

Lee, K.H, Zhang, N., Das, S., 2003. Comparing adaptive neuro-fuzzy inference system (ANFIS) to partial least-squares (PLS) method for simultaneous prediction of multiple soil properties. American Society of Agricultural Engineers, St. Joseph, MI, ASAE paper number: 033144.

Lee, W.S., Slaughter, D.C., 1999. Robotic weed control system for tomatoes. Precision Agriculture (1), 95-113.

Lestander, T.A., Leardi, R., Geladi, P., 2003. Selection of near-infrared wavelengths using genetic algorithms for the determination of seed moisture content. Journal of Near-Infrared Spectroscopy 11 (4), 433-446.

$\mathrm{Li}, \mathrm{X}$., He, Y., Wu, C., 2008. Least square support vector machine analysis for the classification of paddy seeds by harvest year. Transactions of the ASABE 51 (5), 1793-1799.

Lim, C., Sim, E., 2005. Production planning in manufacturing/remanufacturing environment using genetic algorithm. In: Proceedings of the 2005 Conference on Genetic and Evolutionary Computation, Washington, DC, pp. 2217-2218.

Linko, P., Zhu, Y.H., Linko, S., 1992. Application of neural network modeling in fuzzy extrusion control. Food and Bioproducts processing. Transactions IChemE 70, 131-137.

Liu, J., Goering, C.E., Tian, L., 2001. A neural network for setting target corn yields. Transactions of the ASAE 44 (3), 705-713.

Madeiro, S.S., Oliveira, F.R., Alexandre, F.B.A., Neto, F.B., 2006. Intelligent modeling of sugar-cane maturation. In: Proceedings of the 4th World Congress Conference on Computers in Agriculture and Natural Resources, Orlando, FL, pp. 642-648.

Magee, J.F., 1964. Decision trees for decision making. Harvard Business Review July $126-138$

Mamdani, E.H., Assilian, S., 1975. An experiment in linguistic synthesis with a fuzzy logic controller. International Journal of Man-Machine Studies 7, 1-13.

Marchant, J.A., Onyango, C.M., 2003. Comparison of a Bayesian classifier with a multilayer feed-forward neural network using the example of plant/weed/soil discrimination. Computers and Electronics in Agriculture 39, 3-22.

Mathanker, S.K, Weckler, P.R., Taylor, R.K., 2007. Effective spatial resolution for weed detection. American Society of Agricultural and Biological Engineers, St. Joseph, MI, ASABE paper number: 073049.

McCulloch, W.S., Pitts, W.H., 1943. A logical calculus of the ideas immanent in nervous activity. Bulletin of Mathematical Biophysics 5, 115-133.

Melgani, F., Bruzzone, L., 2004. Classification of hyperspectral remote sensing images with support vector machines. IEEE Transactions on Geoscience and Remote Sensing 42 (8), 1778-1790.

Merdun, H., Cinar, Ö., Meral, R., Apan, M., 2006. Comparison of artificial neural network and regression pedotransfer functions for prediction of soil water retention and saturated hydraulic conductivity. Geoderma 90 (1-2), 108-116.

Meyer, G.E., Hindman, T.W., Jones, D.D., Mortensen, D.A., 2004. Digital camera operation and fuzzy logic classification of uniform plant, soil, and residue color images. Applied Engineering in Agriculture 20 (4), 519-529.

Miao, Y., Mulla, D.J., Robert, P.C., 2006. Identifying important factors influencing corn yield and grain quality variability using artificial neural networks. Precision Agriculture 7 (2), 117-135.

Minsky, M., Papert, S., 1969. Perceptrons. MIT Press, Cambridge, MA

Mitra, S., Pal, S.K., 1994. Logical operation based fuzzy MLP for classification and rule generation. Neural Networks 7 (2), 353-373.

Miu, P.I., 2001. Optimal design and process of threshing units based on a genetic algorithm. I. algorithm. American Society of Agricultural Engineers, St. Joseph, MI, ASAE paper number: 013124

Miu, P.I., Perhinschi, M.G., 2001. Optimal design and process of threshing units based on a genetic algorithm. II. Application. American Society of Agricultura Engineers, St. Joseph, MI, ASAE paper number: 013125.

Morimoto, T. Tu, K., Hatou, K., Hashimoto, Y., 2003. Dynamic optimization using neural networks and genetic algorithms for tomato cool storage to minimize water loss. Transactions of the ASAE 46 (4), 1151-1159.

Moshou, D., Vrindts, E., De Ketelaere, B., De Baerdemaeker, J., Ramon, H., 2001. neural network based plant classifier. Computers and Electronics in Agriculture 31, 5-16.

Moshou, D., Ramon, H., De Baerdemaeker, J., 2002. A weed species spectral detector based on neural networks. Precision Agriculture 3 (3), 209-223.

Murray, R., Yule, I., Lawrence, H., 2005. Economic and environmental opportunities from utilizing VRAT from aircraft for improved placement of fertilizer. American Society of Agricultural Engineers, St. Joseph, MI, ASAE paper number: 051075.

Neto, J.C., Meyer, G.E., Jones, D.D., Surkan, A.J., 2003. Adaptive image segmentation using a fuzzy neural network and genetic algorithm for weed detection. American Society of Agricultural Engineers, St. Joseph, MI, ASAE paper number: 033088.

Nie, J., Linkens, D., 1992. Neural network-based approximate reasoning: principles and implementation. International Journal of Control 56 (2) 399-413.

Noguchi, K., Terao, H., 1997. Path planning of an agricultural mobile robot by neural network and genetic algorithm. Computers and Electronics in Agriculture 18 187-204.

Noguchi, N., Reid, J. F., Zhang Q, Tian, L.F., 1998. Vision intelligence for precision farming using fuzzy logic optimized genetic algorithm and artificial neural network. American Society of Agricultural Engineers, St. Joseph, MI, ASAE paper number: 983034

Odhiambo, L.O., Yoder, R.E., Yoder, D.C., 2001a. Estimation of reference crop evapotranspiration using fuzzy state models. Transactions of the ASAE 44 (3), 543-550.
Odhiambo, L.O., Yoder, R.E., Yoder, D.C., Hines, J.W., 2001b. Optimization of fuzzy evapotranspiration model through neural training with input-output examples. Transactions of the ASAE 44 (6), 1625-1633.

Odhiambo, L.O., Freeland, R.S., Yoder, R.E., Hines, J.W., 2004. Investigation of a fuzzy-neural network application in classification of soils using groundpenetrating radar imagery. Applied Engineering in Agriculture 20 (1), 109117.

Oliveira, F.R., Pacheco, D.F., Leonel, A., Neto, F.B., 2006. Intelligent support decision in sugarcane harvest. In: Proceedings of the 4th World Congress Conference on Computers in Agriculture and Natural Resources, Orlando, FL, pp. 456-462.

Onaran, I., Pearson, T.C., Yardimci, Y., Cetin, A.E., 2006. Detection of underdeveloped hazenuts from fully developed nuts by impact acoustics. Transactions of the ASABE 49 (6), 1971-1976.

Oommen, T., Misra, D., Agarwal, A., Mishra, S.K., 2007. Analysis and application of support vector machine based simulation for runoff and sediment yield. American Society of Agricultural and Biological Engineers, St. Joseph, MI, ASABE paper number: 073019.

Ortega, G., Giron-Sierra, J.M., 1995. Genetic algorithms for fuzzy control of automatic docking with a space station. In: Proceedings of IEEE International Conference on Evolutionary Computation, vol. 1, pp. 157-161.

Ortiz, B.V, Perry, C., Sullivan, D.G., Kemerait, B.,Ziehl, A., Davis, R., Vellidis, G., Rucker, K., 2008. Cotton yield response to variable rate nematicides according to risk zones. American Society of Agricultural and Biological Engineers, St. Joseph, MI, ASABE paper number: 081026.

Ovaska, S.J., Vanlandingham, H.F., Kamiya, A., 2002. Fusion of soft computing and hard computing in industrial applications: an overview. IEEE Transactions on Systems, Man and Cybernetics 32 (2), 72-79.

Ovaska, S.J., 2005. Computationally Intelligent Hybrid Systems: The Fusion of Soft Computing and Hard Computing. Wiley-IEEE Press: John Wiley \& Sons, Inc. and the IEEE Press.

Ovaska, S.J., Kamiya, A., Chen, Y.Q., 2006. Fusion of soft computing and hard computing: computational structures and characteristic features. IEEE Transactions on Systems, Man, and Cybernetics, Part C: Applications and Reviews 36 (3), 439-448.

Pabico, J.P., Hoogenboom, G., McClendon, R.W., 1999. Determination of cultivar coefficients of crop models using a genetic algorithm: a conceptual framework. Transactions of the ASAE 42 (1), 223-232.

Pachepsky, Y., Acock, B., 1998. Stochastic imaging of soil parameters to assess variability and uncertainty of crop yield estimates. Geoderma 85 (2-3), 213-229.

Parasuraman, K., Elshorbagy, A., Si, B.C., 2007. Estimating saturated hydraulic conductivity using genetic programming. Soil Science Society of America Journal $71,1676-1684$

Pardo, M., Sberveglieri, G., 2005. Classification of electronic nose data with support vector machines. Sensors and Actuators B 107 (2005), 730-737.

Pearl, J., 1988. Probabilistic Reasoning in Intelligent Systems: Networks of Plausible Inference. Morgan Kaufmann, San Francisco, CA

Pearl, J., 1999. Bayesian Networks. Technical Report (R-246), Revision I, July 1997, MIT Encyclopedia of the Cognitive Sciences, Cambridge, MA.

Pearson, T.C., Wicklow, D.T., 2006. Detection of corn kernels infected by fungi. Transactions of the ASABE 49 (4), 1235-1245.

Peng, Y., Wang, W., 2008. Prediction of pork meat total viable bacteria count using hyperspectral imaging system and support vector machines. In: Proceedings of the Food Processing Automation Conference, Providence, RI, Publication Number 701P0508cd.

Pierna, J.A.F., Volery, P., Besson, R., Baeten, V., Dardenne, P., 2005. Classification of modified starches by Fourier transform infrared spectroscopy using support vector machines. Journal of Agricultural and Food Chemistry 53 (17), 6581-6585.

Pierna, J.A.F., Baeten, V., Dardenne, P., 2006. Screening of compound feeds using NIR hyperspectral data. Chemeometrics and Intelligent Laboratory Systems 84 $114-118$

Potter, W.D., Bi., W., Twardus, D., Thistle, H.W., Ghent, J., Twery, M., Teske, M.E., 2000 A genetic algorithm for aerial spray application optimization. American Society of Agricultural Engineers, St. Joseph, MI, ASAE paper number: 001053.

Pydipati, Y., Burks, T.F., Lee, W.S., 2005. Statistical and neural network classifiers for citrus disease detection using machine vision. Transactions of the ASAE 48 (5), 2007-2014

Qi, F., Zhu, A., Harrower, M., Burt, J.E., 2006. Fuzzy soil mapping based on prototype category theory. Geoderma 136 (3-4), 774-787.

Qi, L., Ma, X. 2009. Rice Blast Detection Using Multispectral Imaging Sensor and Support Vector Machine. American Society of Agricultural and Biological Engineers, St. Joseph, MI, ASAE paper number: 095891.

Qu, G., Feddes, J.J.R., Armstrong, W.W., Coleman, R.N., Leonard, J.J., 2001. Measuring odor concentration with an electronic nose. Transactions of the ASAE 44 (6), 1807-1812.

Raju, K.S., Kumar, D.N., 2004. Irrigation planning using genetic algorithms. Water Resources Research 18 (2), 163-176.

Raju, K.S., Kumar, D.N., Duckstein, L., 2006. Artificial neural networks and multicriterion analysis for sustainable irrigation planning. Computers \& Operations Research 33, 138-153.

Rechenberg, I., 1973. Evolutionstrategie: Optimierung Technisher Systeme nach Prinzipien des Biologischen Evolution. Fromman-Hozlboog Verlag, Stuttgart, Germany.

Rosenblatt, F., 1958. The Perceptron: a probabilistic model for information storage and organization in the brain. Psychological Review 65, 386-408.

Rumelhart, D.E., McClelland, J.L., 1986. Parallel Distributed Processing: Explorations in the Microstructures of Cognition, vol. I. MIT Press, Cambridge, MA 
Rumelhart, D.E., Hinton, G.E., Williams, R.J., 1986a. Learning internal representations by error propagation. In: Rumelhart, D.E., McClelland, J.L. (Eds.), Parallel Distributed Processing: Explorations in the Microstructures of Cognition, vol. I. MIT Press, Cambridge, MA (Chapter 8).

Rumelhart, D.E., Hinton, G.E., Williams, R.J., 1986b. Learning representations by back-propagating errors. Nature 323, 533-536.

Santhanam, S., Langari, R., 1994. Supervisory fuzzy adaptive control of a binary distillation column. In: Proceedings of the Third IEEE International Conference on Fuzzy Systems, vol. 2, Orlando, FL, pp. 1063-1068.

Sayde, C., Khoury, L., Gitelman, A., English, M., 2008. Optimizing estimates of soil moisture for irrigation scheduling. American Society of Agricultural and Biological Engineers, St. Joseph, MI, ASABE paper number: 084699.

Schaap, M.G., Leij, F.J., Van Genuchten, M.T., 1998. Neural network analysis of hierarchical prediction of soil hydraulic properties. SSSA Journal 62 (4), 847-855.

Schwefel, H.P., 1981. Numerical Optimization of Computer Model. John Wiley \& Sons, New York.

Shao, Y., Zhao, C., He, Y., Bao, Y., 2009. Application of infrared spectroscopy technique and chemometrics for measurement of components in rice after radiation. Applied Engineering in Agriculture 52 (1), 187-192.

Shapiro, J., 1998. Genetic algorithms in machine learning. http://citeseerx. ist.psu.edu/viewdoc/summary?doi=10.1.1.22.5158.

Shi, X., Zhu, A., Burt, J.E., Qi, F., Simonson, D., 2004. A case-based reasoning approach to fuzzy soil mapping. Soil Science Society of America Journal 68, 885894.

Sick, B., Ovaska, S.J., 2007. Fusion of soft and hard computing: multi-dimensional categorization of computationally intelligent hybrid systems. Neural Computing and Applications $16(2), 125-137$.

Simpson, P.K., Jahns, G., 1993. Fuzzy min-max neural networks for function approximation. In: Proc. IEEE Int. Conf. on Neural Networks, vol. 3, pp. 19671972.

Smith, E.T., 1993. Why the Japanese are going in for this 'fuzzy logic'? Business Week, February 20, 39.

Sui, R., Thomasson, J.A., 2006. Ground-based sensing system for cotton nitrogen status determination. Transactions of the ASABE 49 (6), 1983-1991.

Sun, T., Ying, Y., Liu, K., Xu, H., 2008. Comparison of chemometrics methods for assessing internal quality of pears on-line using visible/near infrared transmission technique. In: Proceedings of the Food Processing Automation Conference, Providence, RI, Publication Number: 701P0508cd.

Suzuki, Y., Okamoto, H., Kataoka, T., 2009. Development of discriminant model for weed detection using hyperspectral imagery. In: Abrigo, L.G., Ehsani, R. (Eds.), ISHS Acta Horticulturae 824: International Symposium on Application of Precision Agriculture for Fruits and Vegetables. International Society for Horticultural Science, pp. 67-73.

Takagi, T., Hayashi, I., 1991. NN-driven fuzzy reasoning. International Journal of Approximate Reasoning 5 (3), 191-212.

Tang, L., Tian, L., Steward, B.L., 2000. Color image segmentation with genetic algorithm for in-field weed sensing. Transactions of the ASAE 43 (4), 1019-1027.

Tang, L., Tian, L., Steward, B.L., 2003. Classification of broadleaf and grass weeds using Gabor wavelets and an artificial neural network. Transactions of the ASAE 46 (4), 1247-1254.

Tani, T., Utashiro, M., Umano, M., Tanaka, K., 1994. Application of practical fuzzyPID hybrid control system to petrochemical plant. In: Proceedings of Third IEEE International Conference on Fuzzy Systems, vol. 2, Orlando, FL, pp. 1211-1216.

Teorey, T.J., 1999. Database Modeling and Design. Morgan Kaufmann Publishers, San Francisco, CA.

Terano, T., Asai, K., Sugeno, M., 1994. Applied Fuzzy Systems. Academic Press, Inc., Boston, MA.

Thomson, S.J., Peart, R.M., Mishoe, J.W., 1993. Parameter adjustment to a crop model using a sensor-based decision support system. Transactions of the ASAE 36 (1), 205-213.

Thomson, S.J., Ross, B.B., 1996. Dynamic parameter adjustment method for a modelbased irrigation management system. Computers and Electronics in Agriculture $14,269-290$

Thomson, S.J., 1998. Expert systems for self-adjusting process simulation. In: Curry, R.B., Peart, R.M. (Eds.), Agricultural Systems Modeling and Simulation. Marcel Dekker, New York, pp. 157-195.

Thorp, K.R., Tian, L., Yao, H., Tang, L., 2004. Narrow-band and derivative-based vegetation indices for hyperspectral data. Transactions of the ASAE 47 (1), 291-299.

Tian, L.F., Slaughter, D.C., 1998. Environmentally adaptive segmentation algorithm for outdoor image segmentation. Computers and Electronics in Agriculture 21 (3), 153-168.

Tian, Y., Zhang, C., Li, C., 2004. Study on plant disease recognition using support vector machine and chromaticity moments. Transactions of Chinese Society of Agricultural Machinery 35 (3), 95-98.

Tikk, D., Koczy, L.T., Gedeon, T.D., 2003. A survey on universal approximation and its limits in soft computing techniques. International Journal of Approximate Reasoning 33 (2), 185-202.

Trebar, M., Steele, M., 2008. Application of distributed SVM architectures in classifying forest data cover types. Computers Electronics in Agriculture 63 (2), 119-130.

Tumbo, S.D., Wagner, D.G., Heinemann, P.H., 2002a. Hyperspectral-based neural network for predicting chlorophyll status in corn. Transactions of the ASAE 45 (3), 825-832.

Tumbo, S.D., Wagner, D.G., Heinemann, P.H., 2002b. On-the-go sensing of chlorophyll status in corn. Transactions of the ASAE 45 (4), 1207-1215.
Twarakavi, N.K.C., Simunek, J., Schaap, M.G., 2009. Development of pedotransfer functions for estimation of soil hydraulic parameters using support vector machines. Soil Science Society of America Journal 73, 1443-1452.

Uno, Y., Prasher, S.O., Lacroix, R., Goel, P.K., Karimi, Y., Viau, A., Patel, R.M., 2005 Artificial neural networks to predict corn yield from compact airborne spectrographic imager data. Computers and Electronics in Agriculture 47 (2), 149161.

Van Alphen, B.J., Stoorvogel, J.J., 2000. A functional approach to soil characterization in support of precision agriculture. Soil Science Society of America Journal 64 1706-1713.

Wall, M.B., 1996. A Genetic Algorithm for Resource-Constrained Scheduling. Ph.D. Dissertation. MIT, Cambridge, MA.

Walthall, C., Dulaney, W., Anderson, M., Norman, J., Fang, H., Liang, S., 2004. A comparison of empirical and neural network approaches for estimating corn and soybean leaf area index from Landsat ETM+ imagery. Remote Sensing of Environment 92, 465-474.

Wang, W., Paliwal, J., 2006. Spectral data compression and analyses techniques to discriminate wheat classes. Transactions of the ASABE 49 (5) 1607-1612.

Wardlaw, R., Bhaktikul, K., 2004. Application of genetic algorithms for irrigation water scheduling. Irrigation and Drainage 53, 397-414.

Werbos, P.J., 1974. Beyond Regression: New Tools for Prediction and Analysis in the Behavioral Sciences. Doctoral Dissertation. Applied Mathematics, Harvard University, Boston, MA.

Whittaker, A.D., Park, B.S., McCauley, J.D., Huang, Y., 1991. Ultrasonic signal classification for beef quality grading through neural networks. In: Automated Agriculture for the 21st Century-Proc. 1991 Symp. ASAE, St. Joseph, MI, pp. 116-125.

Wilkinson, R.H., 1963. A method of generating functions of several variables using analog diode logic. IEEE Transactions on Electronic Computers 12 112-129.

Witten, I.H., Frank, E., 2000. Data Mining: Practical Machine Learning Tools and Techniques with JAVA Implementations. Morgan Kaufmann Publishers, San Francisco, CA.

Wu, D., Feng, L., He, Y., Bao, Y., 2008. Variety identification of Chinese cabbage seeds using visible and near-infrared spectroscopy. Transactions of the ASABE 51 (6) 2193-2199.

Xiang, H., Tian, L.F., 2007. Artificial intelligence controller for automatic multispectral camera parameter adjustment. Transactions of the ASABE 50 (5) 1873-1881.

Yang, C.C., Prasher, S.O., Mehuys, G.R., Patni, N.K., 1997a. Application of artificia neural networks for simulation of soil temperature. Transactions of the ASAE 40 (3), 649-656.

Yang, C.C., Prasher, S.O., Sreekanth, S., Patni, N.K., Masse, L., 1997b. An artificial neura network model for simulating pesticide concentrations in soil. Transactions of the ASAE 40 (5), 1285-1294.

Yang, C.C., Prasher, S.O., Landry, J.A., Perret, J., Ramaswamy, H.S., 2000a. Recognition of weeds with image processing and their use with fuzzy logic for precision farming. Canadian Agricultural Engineering 42 (4), 195-200.

Yang, C.C., Prasher, S.O., Landry, J.A., Ramaswamy, H.S., Ditommaso, A., 2000b. Application of artificial neural networks in image recognition and classification of crop and weeds. Canadian Agricultural Engineering 42 (3), 147-152.

Yang, C.C., Prasher, S.O., Whalen, J., Goel, P.K., 2001. Application of data mining technology for hyperspectral imagery classification in agricultural fields. American Society of Agricultural Engineers, St. Joseph, MI, ASAE paper number 013116.

Yang, C.C., Prasher, S.O., Landry, J.A., Ramaswamy, H.S., 2002. Development of neural networks for weed recognition in corn fields. Transactions of the ASAE 45 (3), 859-864.

Yang, C.C., Prasher, S.O., Landry, J., Ramaswamy, H.S., 2003. Development of an image processing system and a fuzzy algorithm for site-specific herbicide applications. Precision Agriculture 4 (1), 5-18.

Yang, C.C., Prasher, S.O., Goel, P.K., 2004a. Differentiation of crop and weeds by decision tree analysis of multi-spectral data. Transactions of the ASAE 47 (3), 873-879.

Yang, C.C., Prasher, S.O., Lacroix, R., Kim, S.H., 2004b. Application of multivariate adaptive regression splines (MARS) to simulate soil temperature. Transactions of the ASAE 47 (3), 881-887.

Yao, H., Tian, L., 2003. A genetic algorithm-based selective principal component analysis (GA-SPCA) method for high dimensional data feature extraction. IEEE Transactions on Geoscience and Remote Sensing 41 (1), 14691478

Yasunobu, S., Miyamoto, S., 1985. Automatic train operation system by predictive fuzzy control. In: Sugeno, M. (Ed.), Industrial Applications of Fuzzy Control. North-Holland, pp. 1-18.

Yu, H., Niu, X., Ying, Y., Pai, X., 2008. Non-invasive determination of enological parameters of rice wine by Vis-NIR spectroscopy and least squares support vector machines. American Society of Agricultural and Biological Engineers, St Joseph, MI, ASABE paper number: 084875.

Zadeh, L.A., 1965. Fuzzy sets. Information and Control 8, 338-353.

Zadeh, L.A., 1973. Outline of a new approach to the analysis of complex systems and decision processes. IEEE Transactions on Systems, Man, and Cybernetics SMC-3 28-44.

Zadeh, L.A., 1981. Possibility theory and soft data analysis. In: Cobb, L., Thrall, R.M (Eds.), Mathematical Frontiers of the Social and Policy Sciences. Westview Press, Boulder, CO, pp. 69-129. 
Zadeh, L.A., 1992. Foreword. In: Proceedings of the Second International Conference on Fuzzy Logic and Neural Networks, Iizuka, Japan, pp. xiii-xiv.

Zhang, Z.X., Kushwaha, R.L., 1999. Application of neural networks to simulate soil-tool interaction and soil behavior. Canadian Agricultural Engineering 41 (2), 119-125.

Zhang, H., Paliwal, J., Jayas, D.S., White, N.D.G., 2007. Classification of fungal infected wheat kernels using near-infrared reflectance hyperspectral imaging and support vector machine. Transactions of the ASABE 50 (5), 1779-1785.
Zhang, Q., Litchfield, J.B., 1992. Advanced process controls: applications of adaptive, fuzzy and neural control to the food industry. In: Food Processing Automation II. ASAE, St. Joseph, MI, pp. 169-176.

Zhu, A., Hudson, B., Burt, J., Lubich, K., Simonson, D., 2001. Soil mapping using GIS, expert knowledge, and fuzzy logic. Soil Science Society of America Journal 65, 1463-1472.

Zhu, A., Yang, L., Li, B., Qin, C., Pei, T., Liu, B., in press. Construction of membership functions for predictive soil mapping under fuzzy logic. Geoderma. 